\title{
Secuencia de cerámica paracas en Pallaucha, VILCASHUAMÁN - AyACUCHO
}

\author{
Edison Mendoza Martinez ${ }^{a}$
}

\begin{abstract}
Resumen
El presente artículo expone los resultados obtenidos de las excavaciones en el sitio del Periodo Formativo Pallaucha, ubicado al sur de Ayacucho, en la cuenca del rio Pampas. Hasta hace pocos años, Ayacucho se consideraba como un área sin mucha importancia durante el Periodo Formativo; sin embargo, las últimas evidencias podrian cambiar esa imagen, y a se ha encontrado arquitectura monumental compleja asociada a material cultural procedente de diversas áreas; una de ellas es la Costa Sur. Materiales procedentes de esta parte de la costa peruana son importantes, no solo porque la costa de Paracas se halla relativamente cerca de Ayacucho, sino porque aparecen en todos los sitios del Periodo Formativo. Durante las excavaciones en Pallaucha, se ha encontrado secuencia de tres fases de cerámica Paracas, lo que sugiere relaciones estrechas con la Costa Sur. En este trabajo, describiremos sus contextos asociados.
\end{abstract}

Palabras clave: Periodo Formativo, Paracas, cuenca del río Pampas

Abstract

A PARACAS CERAMIC SEQUENCE FROM PALLAUCA, VILCASHUAMÁN-AYACUCHO

This article presents the results of excavations carried out at the Formative Period site of Pallaucha, located south of Ayacucho, in the basin of the Pampas River. Until recently, Ayacucho was considered a minor area during the Formative Period; however, this idea could change thanks with the discovery of complex architecture associated to cultural materials coming from different area; one of them the South Coast. Three ceramic phases were identified during excavations at Pallaucha, which suggests a close relationship between this site and the South Coast. In this paper we describe the associated contexts.

Keywords: Formative Period, Paracas, drainage of the Pampas River

a Correo electrónico: edisonmma@hotmail.com 


\section{Introducción}

El sitio arqueológico de Pallaucha se compone de cuatro montículos (I, II, III y IV) y está rodeado por muros a manera de plataformas escalonadas. Tres de los montículos se encuentran alineados en eje longitudinal. En la superficie, se encuentra abundante material cultural del Período Formativo.

Este sitio se encuentra ubicado a 6,3 kilómetros al lado este de la capital de la provincia de Vilcashuamán, departamento de Ayacucho, 117 kilómetros al sur de Huamanga. Se puede llegar tomando la trocha carrozable que comunica Vilcashuamán con el distrito de Saurama o Carhuanca hasta las alturas del kilómetro 64. En la cartografía geográfica, la zona medular del complejo arqueológico se ubica entre las coordenadas UTM 0618883.215 E 8486782.13 N, y se encuentra a una altitud de 3762 metros sobre el nivel del mar. El sitio tiene una extensión aproximada de 44,2 hectáreas.

Pallaucha, según la clasificación de Pulgar (1981), se localiza en la región suni. La planicie se caracteriza por ser un territorio casi plano con áreas de bofedales y cuatro lagunas (Pallaucha, Qucharakan y Vizkachayuq, dividida en China y Urqu). Se pueden distinguir básicamente dos estaciones: una con lluvias intensas durante los meses de enero a marzo y otra seca de abril hasta mediados de diciembre. La temperatura en la época seca desciende hasta los $0{ }^{\circ} \mathrm{C}$; en los depósitos de agua, se observan capas delgadas de hielo. Por su parte, en la época de lluvia, la temperatura es mucho más cálida por el hecho de que se halla nublada. Según los pobladores de la zona, cuando el año es bueno, aparecen las aves llamadas jillwas y chillan a orillas de las lagunas; cuando estas no aparecen, se augura un mal año. En lo que respecta a agricultura, en la actualidad, en la planicie, se cultivan papa, oca, mashua, olluco y granos, como la quinua. Otra característica a resaltar de la planicie es que se halla en una hondonada circundada por cerros con altitudes que oscilan entre 3200 y 4182 metros sobre el nivel del mar. Se debe precisar que este es el único terreno plano de mayores dimensiones dentro de la circunscripción de Vilcashuamán.

Las investigaciones sobre el Período Formativo en la región de Ayacucho se han concentrado básicamente en la capital del departamento y áreas cercanas (Flores 1960: 335; Cruzatt 1971: 605; Lumbreras 1974: 73; Ochatoma 1998: 292-293). En todas estas investigaciones, se afirmaba que, durante el Periodo Formativo, «Ayacucho tenía más bien el carácter de una sociedad aldeana, de base rural, mientras que Chavín y sus similares eran sociedades que estaban procesando una configuración urbana pujante» (Lumbreras 1974: 73). Ello fue reforzado por Burger (1993: 179-180). Sin embargo, Matsumoto y Cavero, con sus últimas investigaciones en Campanayuq Rumi, un sitio en forma de «U», "[...] indican que es necesario cambiar esta imagen. Campanayuq Rumi es el centro ceremonial del Periodo Formativo más grande que se haya descubierto en toda la sierra centro-sur del Perú y, tal vez, uno de los complejos más importantes de la zona» (2009: 324). En este contexto, como parte de nuestra tesis de maestría en la PUCP, por referencia de Pérez et al. (2007: 126), realizamos trabajos de prospección en las cercanías de Campanayuq Rumi, lo que dio como resultado el registro de otro sitio del Período Formativo denominado Pallaucha (Fig. 1). Las investigaciones revelaron que el sitio trata de tres montículos alineados longitudinalmente, a semejanza de sitios de la sierra norte, como Kuntur Wasi, Huacaloma. Así también, las excavaciones en el sitio evidenciaron la presencia de cerámica Paracas en toda su secuencia desde el Período Formativo Tardío hasta el Período Epiformativo. Por la temática de la publicación, nos centraremos principalmente en las evidencias que corresponden a Paracas.

\section{Antecedentes e investigaciones en Pallaucha}

Pallaucha fue inicialmente mencionado por los ayudantes de Julio C. Tello cuando pasaban por la cuenca del río Pampas «[...] las ruinas de Pallancha, situados en la pampa del mismo nombre, estas ruinas que están en un promontorio de más o menos sesenta metros están formadas por habitaciones rústicas encerradas en corralones rectangulares hechas de las mismas piedras [...]» (Carrera et al. 2014 [1945-1946]: 32). Posteriormente, en 1959, Carlos Guzmán Ladrón de Guevara planteó 


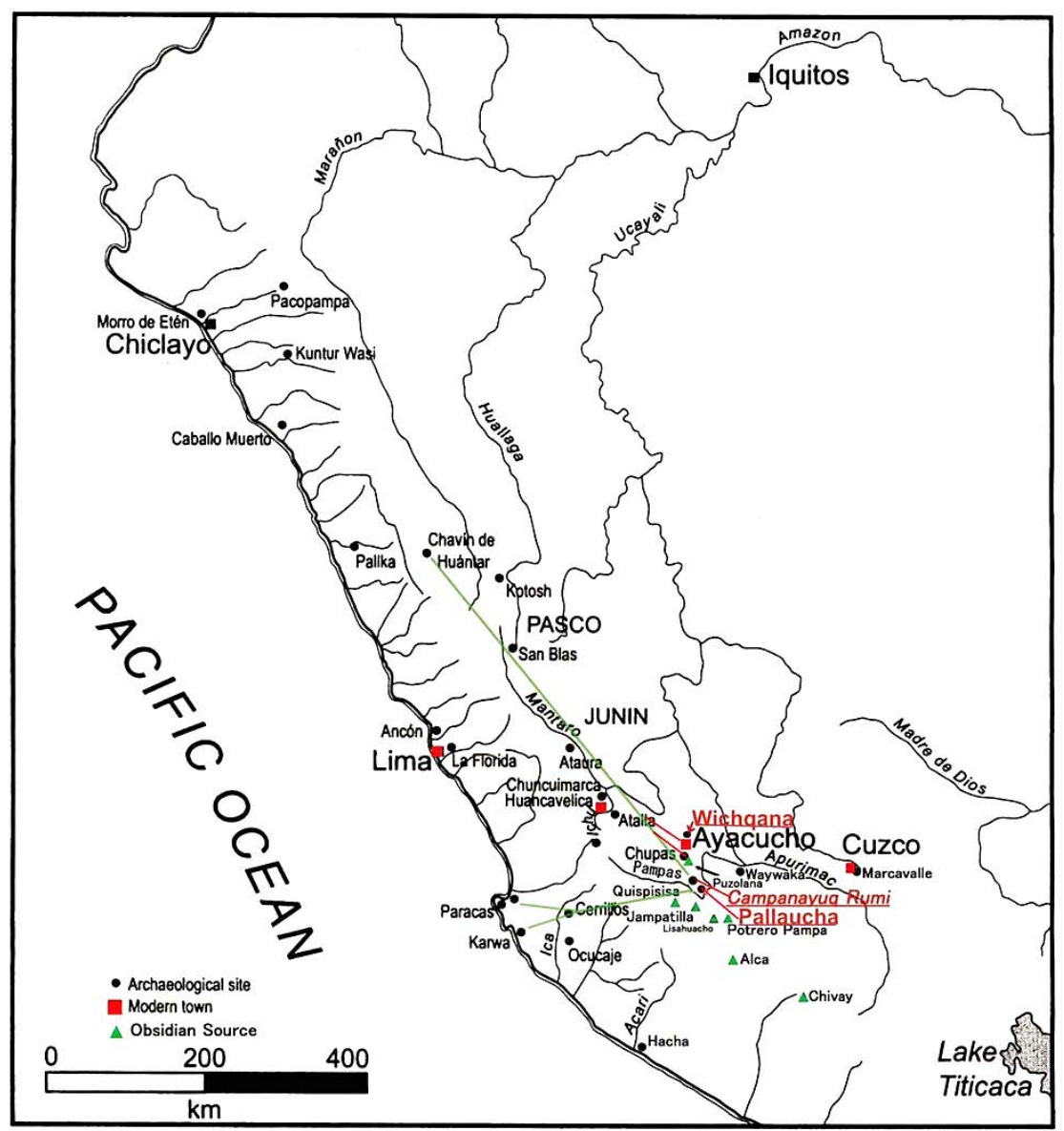

Figura 1. Ubicación de sitios monumentales del Periodo Formativo en Ayacucho [(modificado de Burger y Matos 2002: 154)] (Matsumoto 2010: 411) (modificación: Edison Mendoza).

referencias de sitios cercanos, como Toro Rumi, «En la zona de Putaqa, cerca a Vilcashuamán fueron halladas aproximadamente 15 puntas de flechas, de pedernal. Los proyectiles los encontró Leocadio Sullca, vecino del lugar en el sitio conocido como Puca Puca, Lugar donde hay gran cantidad de rocas y piedras. Los dardos los encontró posiblemente en el sitio de Toro Rumi, no supo dar la ubicación exacta. Toro Rumi es un cerro donde existe gran cantidad de pedernal en bruto. Estos proyectiles pueden indicar tal vez la existencia de sitios pre-cerámicos en la zona» (Guzmán 1959: 60). Este mismo sitio es mencionado como Putaja por Lumbreras (1959: 70). De acuerdo con nuestros trabajos de campo, Toro Rumi se halla cerca de Pallaucha. El Toro Rumi que registramos trata de una planicie en la parte sur de Pallaucha y no de un cerro. Además, en nuestra prospección, no hallamos evidencia cultural significativa. Es probable que, por la cercanía a Pallaucha, tal vez, Toro Rumi esté haciendo referencia a Pallaucha, puesto que es el único lugar donde se puede encontrar abundante nódulo de obsidiana y puntas de proyectil.

En 2007, Pérez et al. presentan un libro sobre los inkas, en el cual hacen mención a dos sitios del Período Formativo: Campanayuq Rumi y Pallaucha. Sobre este último, se indica: «[...] trata de por lo menos dos promontorios alargados dispuestos con eje longitudinal este - oeste, separados uno del otro por una pampa, que contiene abundante material cultural de superficie» (Pérez et al. 2007: 126). Al respecto, se debe precisar que esta es la primera vez que se menciona sobre la ocupación formativa en el sitio. 


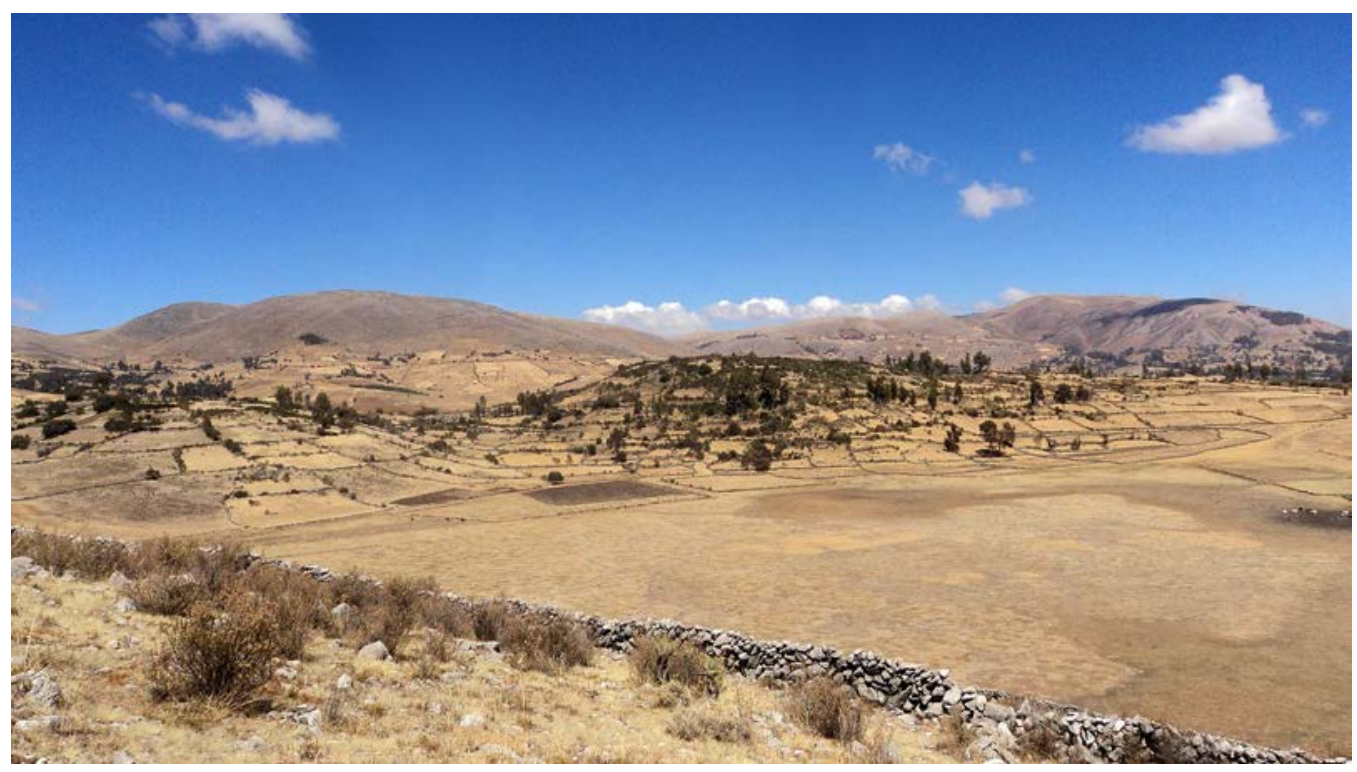

Figura 2. Vista panorámica de los tres montículos, de norte a sur. M-I: Kichka Pata, M-II: Llaulli Pata, M-III: Urqupa Punkun (elaboración: Edison Mendoza).

Posteriormente, nosotros, en 2010, como parte de nuestro informe para obtener el grado de bachiller en la Universidad Nacional de San Cristóbal de Huamanga, lo registramos con el nombre de Llaulli Pata. En ese entonces, sugeríamos que la arquitectura en monumentalidad era similar a Campanayuq Rumi y Atalla (Mendoza 2010: 148).

\subsection{El sitio arqueológico Pallaucha}

El sitio arqueológico de Pallaucha se compone de cuatro montículos (I, II, III y IV), tres de los cuales se encuentran alineados. Los moradores de la zona denominan a cada montículo con nombres distintos: al Montículo I, como Kichka Pata; al Montículo II, Llaulli Pata; al Montículo III, Urqupa Punkun; y al Montículo IV, Pincha Pata. Para unificar criterios, tomaremos en cuenta el nombre de la planicie circundante al sitio, Pallaucha, en toda la planicie hemos encontrado cerámica del Periodo Formativo (Figs. 2 y 3).

El Montículo I es una lomada natural, nivelada en la parte superior a manera de una plataforma de forma redondeada de aproximadamente con 70 metros de diámetro. Está delimitada por un muro de 60 centímetros de ancho y altura de 50 centímetros. Encima de esta, se hallan estructuras circulares de diámetros que oscila de tres a cinco metros en un número de 10 dispuestos sin orden. Igualmente, sobre la ladera del montículo, se hallan terrazas cortas de 30 a 40 metros de largo orientadas de norte a sur, con una altura aproximada que osilla de uno a 2,10 metros, construidas con bloques de piedras pequeńas en nada comparables con los líticos del Montículo II. La mayor parte del sitio se halla disturbada, puesto que responden a terrenos de cultivo.

El Montículo II está rodeado de, por lo menos, dos terrazas de piedra que sobrepasan los tres metros de altura. La cima tiene relieve plano de forma rectangular, visto de planta de 120 por 120 metros aproximadamente. En sus lados laterales, en la parte inferior de la cuesta, se encuentran restos de terrazas, algunas largas y otras cortas, entre 20 a 50 metros. En la parte central alta de esta plataforma, se observan cabeceras o cimientos de estructuras circulares similares a las observadas en el Montículo I. Actualmente, el sitio sirve como corrales de pasto.

Los trabajos de limpieza en las dos terrazas que rodean el Montículo II nos han ayudado a definir que estas terrazas no solo eran lineales, sino que tenían una planta escalonada (ubicada en la parte 


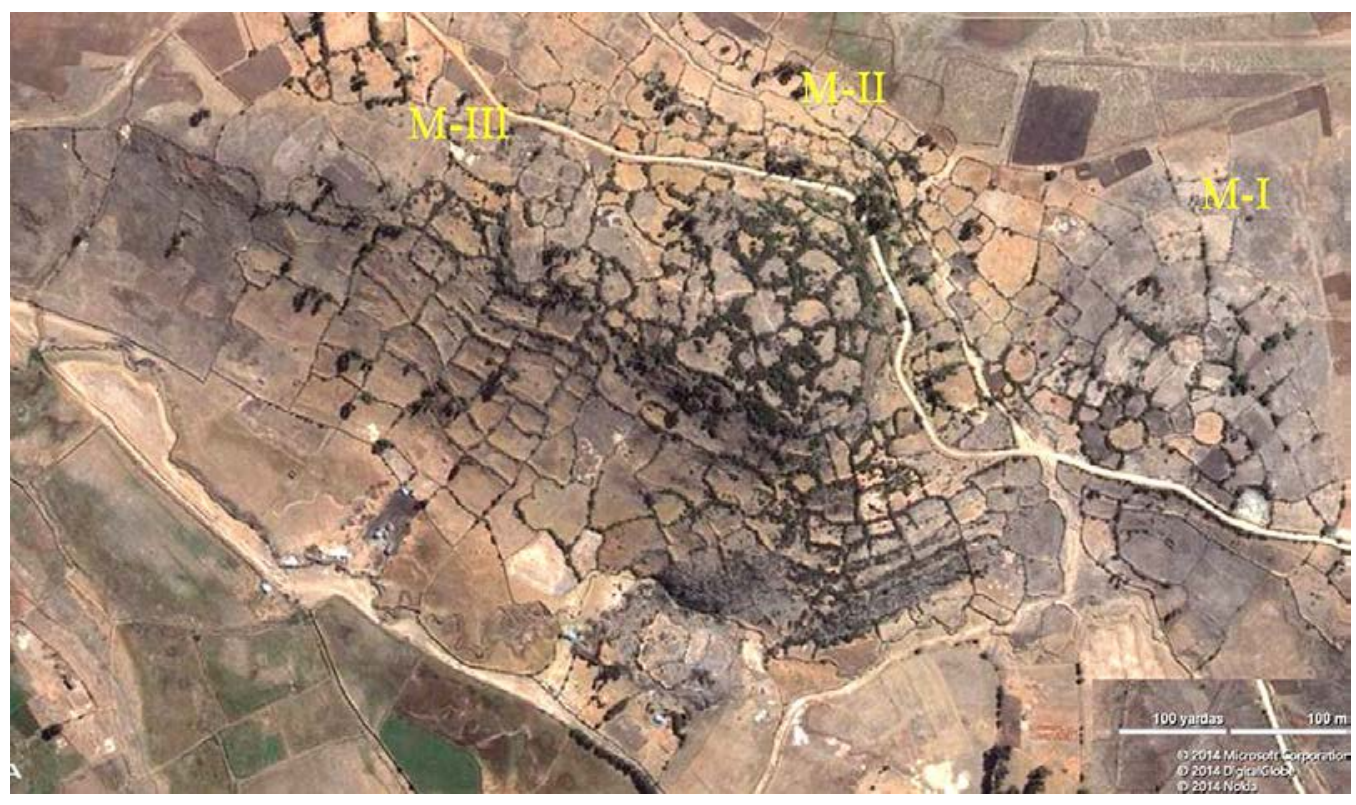

Figura 3. Vista en planta del sitio arqueológico Pallaucha, véase los tres montículos (M-I, M-II y M-III), nótese su disposición lineal. El sitio es cortado en dos por la carretera Vilcashuamán-Carbuanca (fuente: Google Earth, elaboración: Edison Mendoza).

central de cada una de las ellas). En algunos casos, como en el lado sur, la terraza tiene hasta tres esquinas de planta escalonada. Este mismo patrón se repite en algunas terrazas de todo el complejo, lo cual da la idea de que se trata de arquitectura decorativa. En este mismo montículo, en el lado oeste, en la parte central de la Terraza 1 , hemos notado una escalinata de dos peldańos de aproximadamente 1,50 metros de ancho. Los peldaños tienen un ancho de 20 a 25 centímetros y altura de 15 a 25 centímetros, Los peldaños están constituidos por líticos dispuestos de forma horizontal de sureste a noroeste; estos no están amarrados con los muros laterales. Por su parte, los muros laterales sí presentan amarres en su disposición; es decir, en una fila, las piedras están dispuestas de largo y las piedras de encima de la segunda fila en posición contraria. Cabe anotar que esta técnica no se evidencia en otras terrazas. Para ver la continuidad de dicha escalinata, investigamos la Terraza 2 de la parte inferior; sin embargo, por las observaciones que realizamos en el paramento, no lo pudimos determinar. Esta terraza podría pertenecer a otra fase posterior o, en todo caso, la escalinata que se proyecta por debajo del muro. Por ahora, nos limitamos a dar mayores juicios. No descartamos también una disposición de tipo caracol; es decir, la continuidad de la escalinata se halla en otro extremo en un lugar que todavía no conocemos (Figs. 4 y 5). Finalmente, por el tamaño de la escalinata, descartamos que haya tenido la función de movilidad permanente. Tal vez, fue diseńada para ser vista, no para ser caminada, relacionada con aspectos estéticos y rituales. Similar caso se observaría en las terrazas que adornan la lomada y las laderas adyacentes.

El Montículo III está separado del primero por una hondonada. Este es más bajo que el Montículos I y II, rodeado de por los menos una terraza. Los muros no sobrepasan los 3 metros de altura. En la parte superior, forman una plataforma casi rectangular de 100 por 30 metros, aproximadamente. Su disposición es paralela al primero. Al lado norte, se observan tres terrazas largas de 50 metros de largo, dispuestas longitudinalmente de este a oeste a manera de plataformas escalonadas. El montículo básicamente está circunscribiendo un área de rocas. El tipo de muro que rodea este montículo es similar al Montículo II. En este caso, los líticos no solamente están dispuestos de forma horizontal, sino también verticalmente (al lado este). En la parte más alta, se observan alineaciones de muros con piedras pequeñas, que insinúan una estructura rectangular a manera de 


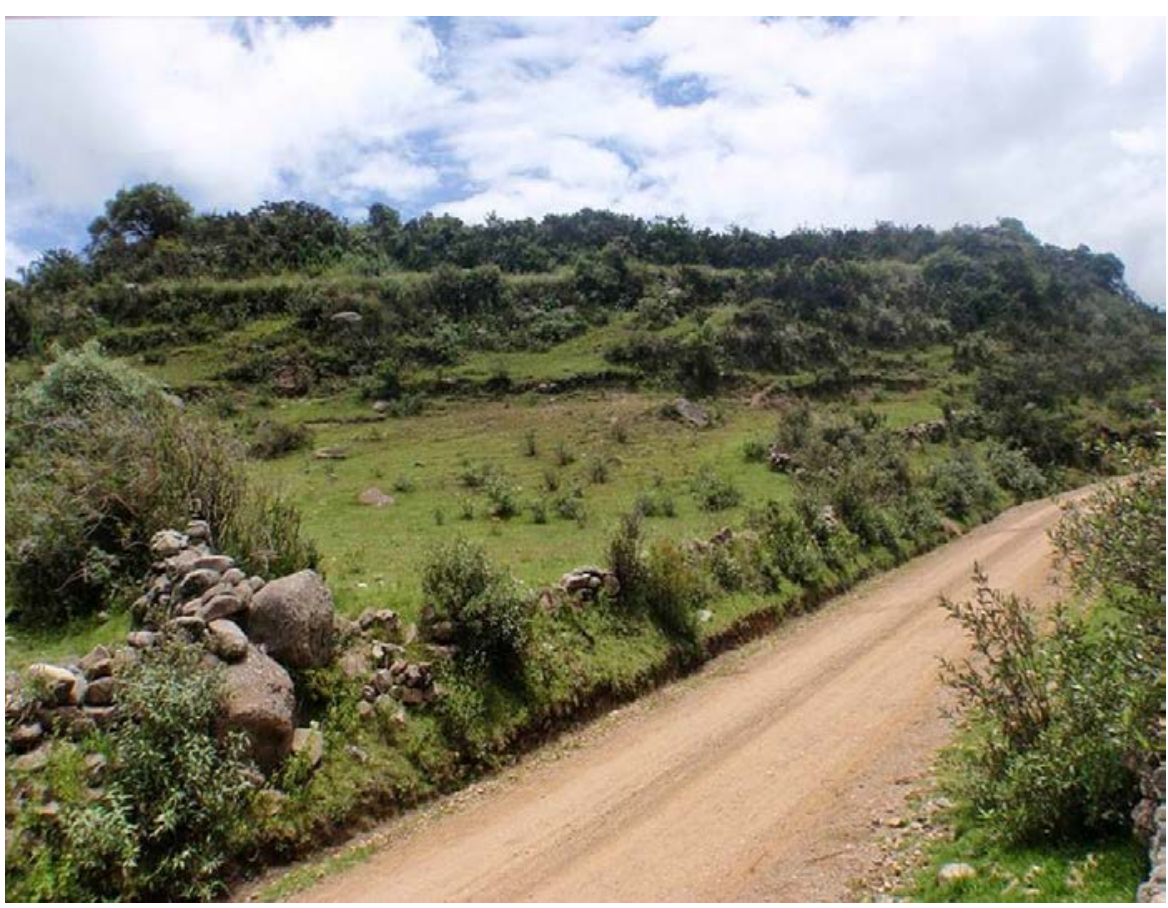

Figura 4. Lado este del montículo II, véase las dos terrazas que circundan el montículo, cubierta con abundante vegetación arbustiva principalmente por el llaulli y chachas (foto: Edison Mendoza).

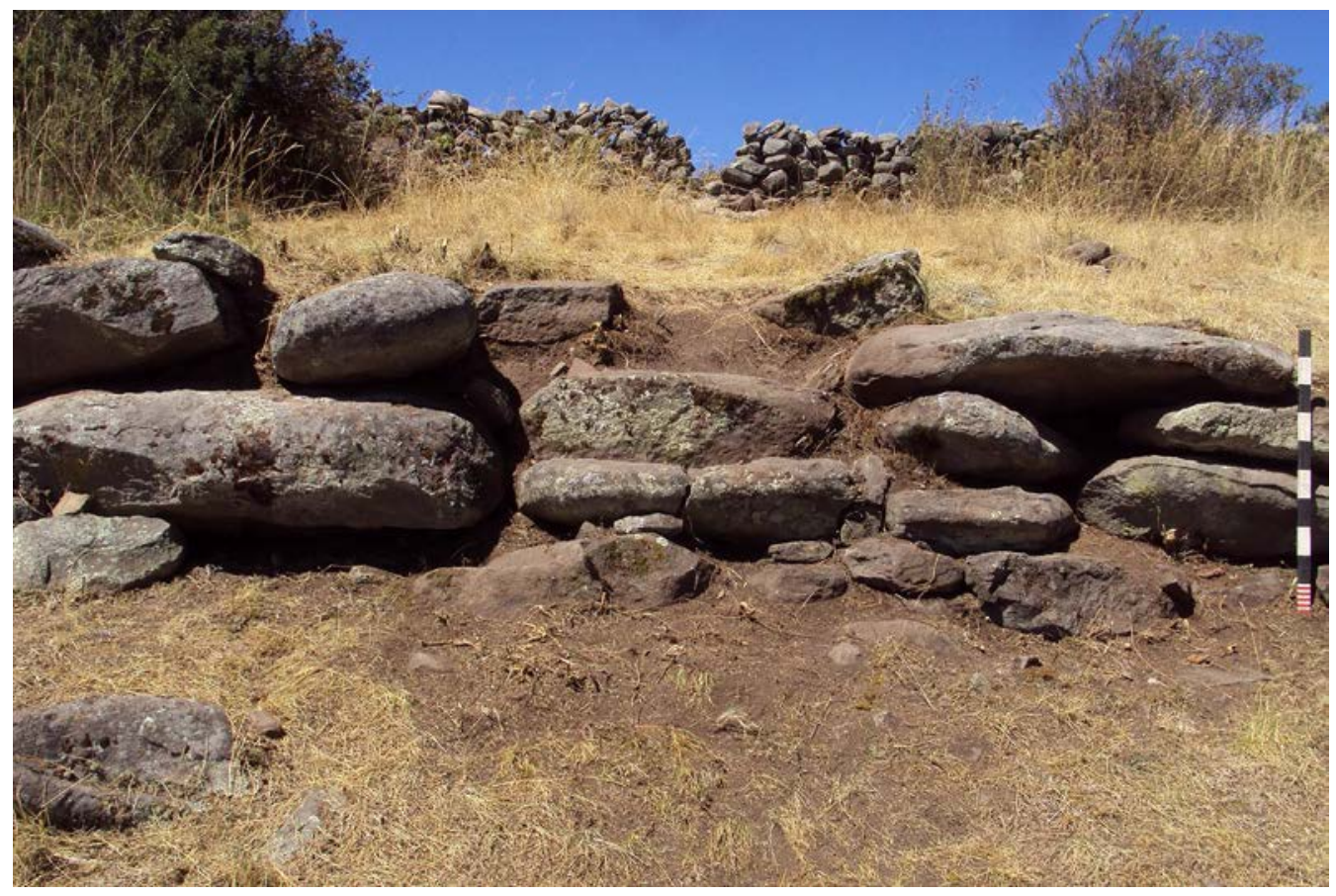

Figura 5. Escalinata de dos peldaños en el lado oeste del montículo II, de $1.50 \mathrm{~cm}$ de ancho (foto: Edison Mendoza). 
entrada a una galería y a una cista circular disturbada. Junto a esta, casi en la parte central, se hallan cuatro bloques grandes de piedra.

La parte media entre los Montículos II y III mide unos 55 por 60 metros. Es de resaltar que, en sus lados norte y sur, se encuentran terrazas que encierran este espacio. En este caso, los líticos no solamente se disponen de forma horizontal, sino también verticalmente a manera de ortostatos. En la pampa, se observan bases de algunos muros. Asimismo, al lado sur de esta misma pampa, resalta una depresión circular, como una especie de plaza circular hundida con dimensiones aproximadas de 80 por 20 metros.

El Montículo IV se halla en el lado norte de estos tres montículos, aproximadamente a 1 kilómetro, entre las comunidades de Monti Cucho y Huancapuquio. En el sitio, se observan cimientos de muros a similar de los Montículos II y III. Actualmente, esta parte es utilizada como área de sembrío.

En todo el sitio, hemos podido distinguir tres tipos de terrazas. El primero está conformado por bloques de piedra trabajadas, que no solamente guardan relación en cuanto al acabado, sino también en su ordenamiento y/o disposición en los muros. El segundo está formado por piedras semitrabajadas, que están dispuestas con un ligero grado de retoque con esquinas redondeadas. El tercer tipo está formado por bloques de líticos, dispuestos de forma vertical a manera de ortostatos. Estos bloques de piedra, en su mayoría, pesan aproximadamente entre 1 a 2 toneladas similar a los muros de Campanayuq Rumi. El primer tipo forma parte de los sitios más visibles, mientras que el segundo se localiza en las zonas inferiores de los montículos; algunos de ellos, por su disposición, podrían confundirse con terrazas modernas. Mientras tanto, el tercero se ubica principalmente en la parte intermedia de los Montículos II y III.

Las canteras de las que se extraían los líticos para la construcción se hallan en la cima de los mismos montículos. Uno de ellos está localizado en el extremo noreste del Montículo II; y el otro, en el extremo suroeste del Montículo III. En ambos casos, las rocas están en proceso de trabajo. Incluso, se pueden observar dos técnicas: el primero corresponde al relacionado (percusión indirecta); y el otro, mediante el empleo de un percutor (bloque de piedra), que se lanzaba directamente a la roca (percusión directa) que genera fractura. Este último podría parecerse a la percusión bipolar. En algunas rocas, se observa la combinación de ambas técnicas. En las canteras, se evidencia que una cierta cantidad de rocas se estaban empezando a trabajar, es decir, a fragmentar con cincel y a fracturar, pero no terminaron de ser trabajadas. Por ello, es probable que la construcción de las terrazas haya sido una actividad permanente relacionada con los procesos de enterramientos y renovación de otras estructuras.

Finalmente, otra observación de los Montículo I, II, y III es que, a nivel de superficie, se hallan cabeceras o cimientos de estructuras pequeñas de formas circulares y rectangulares, a manera de un sitio del Período Intermedio Tardío.

El montículo con mayor presencia de arquitectura y cerámica es el Montículo II, hecho que nos llevó a realizar los trabajos de investigación. Antes de los trabajos realizados, como las excavaciones arqueológicas y la limpieza de las malezas, el sitio se encontraba cubierto por abundante vegetación arbustiva de espinas, como la taqsana y ayrampu, los mismos que imposibilitaban definir la arquitectura. Asimismo, estaba afectado por la agricultura moderna; la mayoría de las terrazas habían sido alteradas por reacomodos y acondicionamientos para muros y terrazas.

En un inicio, pensamos que el Montículo II trataba de una plataforma ceremonial con una escalinata principal y con arquitectura pública encima de la plataforma. Las excavaciones llevadas encima y al interior de la "plataforma» revelaron la existencia de sucesiones arquitectónicas menores (estructuras circulares como las observadas en la superficie) desde el nivel del suelo estéril. Ello cambió en parte nuestra idea de plataforma: la mayoría de estas estructuras estaban asociadas con artefactos de actividades productivas, como especie de talleres, y también había restos de basura de actividad ritual y doméstica. A continuación, describimos una de las áreas de excavación. 


\section{Excavaciones parte alta del Montículo II}

\subsection{Unidad de excavación 1}

Se ubica en la parte alta central del Montículo II, entre las coordenadas UTM (WGS84): E0618872-N8486788 (esquina noreste de la unidad), a una altitud de 3759 metros sobre el nivel del mar. Tiene una dimensión de 6 por 8 metros, con una ampliación de 2 por 4 metros al lado sureste. Esta unidad fue establecida con el propósito de despejar la presencia de arquitectura pública. Lo que motivó nuestra atención fue un área hundida circular, que parecía responder a una plaza hundida, que se halla en el eje central este a oeste de la plataforma, la misma que está alineada con la escalinata.

A continuación, describiremos el orden de los estratos.

3.1.1. Capa superficial. Consiste en una capa de tierra orgánica de color negro, de consistencia semicompacta, de granulometría mediana-fina, con regular cantidad de piedras subangulosas de tamaño pequeñas y medianas dispersas en la superficie. Como componente orgánico, se observa la cobertura vegetal propia de la zona, como las gramíneas y las plantas espinosas como el ayrampo, llaulli y el ichu. La capa, por su origen, corresponde a un proceso cultural moderno, actualmente sirve como corral de pasto. Esta capa tiene un buzamiento de norte a sur. El espesor de la capa oscila entre 10-25 cm y está dispuesta sobre la capa A-1. En la capa se observa regular cantidad de material cerámico y escaso de lítico.

3.1.2. Capa A-1. Similar a la capa $S$, se diferencia porque en esta se reduce el componente orgánico. Tiene una inclinación de norte a sur; su espesor oscila entre 4 a 30 centímetros y cubre la capa B-1. Luego de excavar en su integridad esta capa, se definieron las cabeceras de tres espacios arquitectónicos (E-A): 1, 2 y 7.

3.1.3. Capa B-1. Consiste en una capa de tierra arcillosa con abundante mica, de color marrón casi rojiza, de consistencia semi compacta y granulometría mediana-fina. Al interior, se observó regular cantidad de piedras pequeñas y medianas; como componente orgánico, se sigue observando raíces. La capa, por su origen, corresponde a un proceso cultural; estaría relacionado con el colapso de los muros de los E-A 1, 2 y 7 (Fig. 6). Tiene un buzamiento de norte a sur. El espesor de la capa oscila entre 10 y 24 centímetros. Además, en ella, se observó abundante cantidad de tiestos de cerámica, líticos y óseos.

3.1.4. Capa C-1 (exterior de los espacios arquitectónicos). En coloración, es similar a la Capa B; sin embargo, se diferencia porque en esta hay un cambio drástico en el tipo de estrato. Asimismo, se observan gran cantidad de ceniza y restos de carbón. Por sus características y su compactación, respondería a un nivel de piso asociado a los E-A 1 y 2 . Esta capa tiene una inclinación de norte a sur y su espesor oscila entre los 10 y 15 centímetros. Luego de definir de manera clara los muros de los E-A 1 y 2, decidimos concentrarnos al interior de cada uno de ellos.

3.1.5. Descripción de los espacios arquitectónicos (E-A). Los E-A tienen un diámetro que oscila de dos a 4,5 metros. Dichos espacios están construidos con piedras de campo (algunos se hallan canteadas) y mortero de barro. Los muros son de doble hilera y tienen un ancho que oscila de 30 a 60 centímetros. En la mayoría de los muros, no solamente se utilizaron piedras de campo, sino también se reutilizaron restos de morteros y batanes fragmentados.

\subsection{La Fase 3}

3.2.1. Espacio arquitectónico 1 . Al interior de esta estructura, se definió la Capa $\mathrm{C}$, la cual, por su espesor, fue dividida en $\mathrm{C} 1$ y $\mathrm{C} 2$. Ambas tienen características similares a la Capa $\mathrm{C} 1$ del exterior. $\mathrm{La}$ C1 responde a la capa de abandono con piedras de colapso del muro, y el inicio de la Capa C2, al nivel de piso del E-A 1. Al interior, no hemos hallado evidencia significativa. 


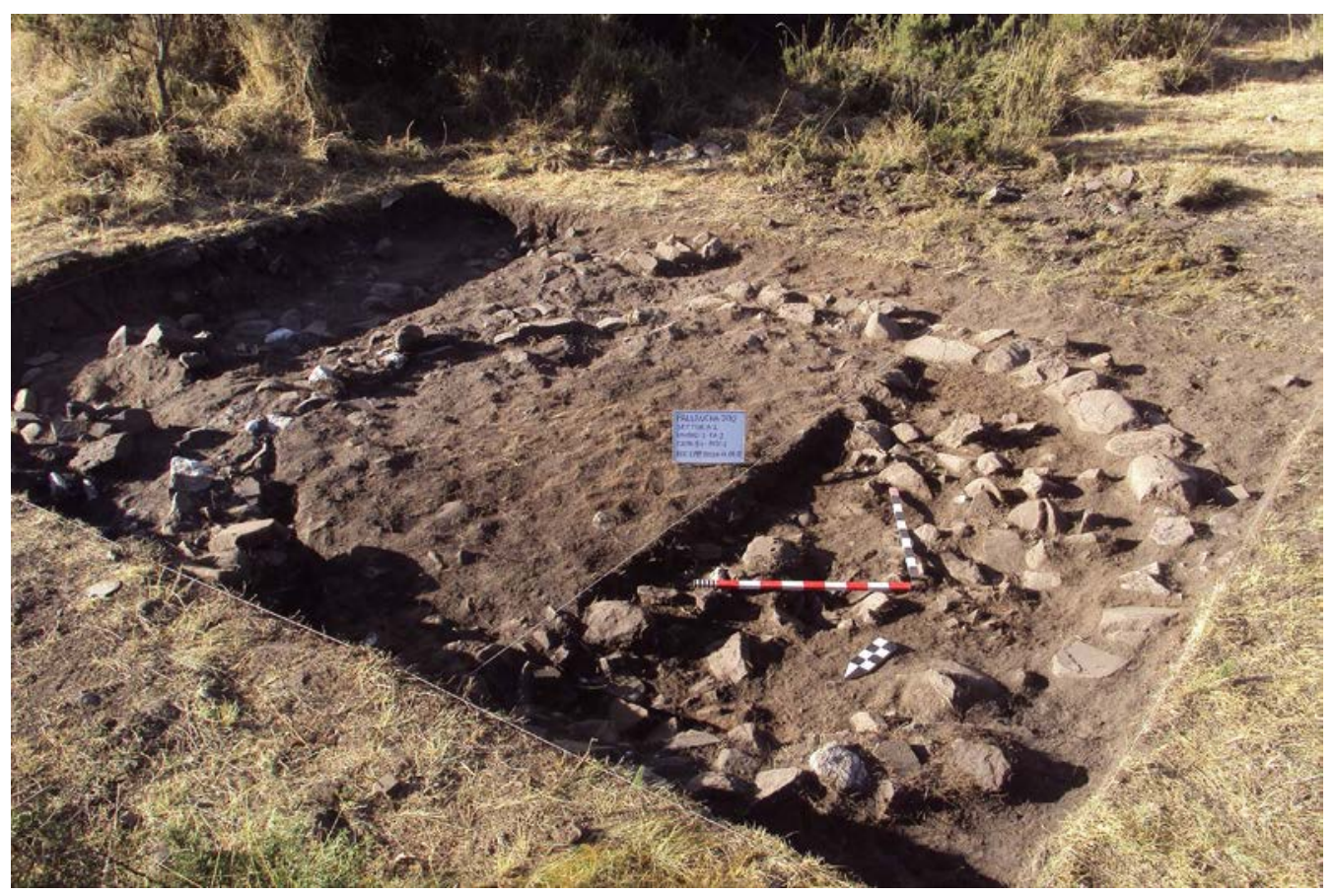

Figura 6. Espacio Arquitectónico $N^{\circ}$ 2. Colapso de piedras encima de piso 1, véase la diferencia con la capa A-1 (foto: Edison Mendoza).

\subsubsection{Espacio arquitectónico 2}

3.2.2.1. Piso 1: Se halla debajo de la Capa B. Consiste en una capa arcillosa con abundante mica de color rojizo, de consistencia casi compacta, de granulometría mediana-fina. Como componente orgánico, se observan raíces, así como gran cantidad de piedras de tamańo regular, las cuales corresponderían al colapso del muro. Entre los bloques de piedra, se recuperó una vasija, casi completa, con decoración de franjas cortadas (similar a la cerámica arqalla). En algunas partes, se hallaron lajas dispuestas horizontalmente, asociadas a bloques de arcilla quemada, al parecer, del enlucido de los muros. Encima de este piso, se observa regular cantidad de cerámica fragmentada, restos quemados, al parecer, de magüe o ichu, y astas quemadas de venado (Fig. 7). Retirado este piso, llegamos a otro (Piso 2) asociado a mayor cantidad de carbón, que fue definido como Contexto 1. Este se compone de un disco de piedra con hoyuelo (porra), cerámica fragmentada y un mortero intencionalmente invertido (Figs. 7 y 8). Se debe anotar que el Piso 1 es una remodelación tardía del Piso 2; ambos pisos tienen el mismo tipo de material cerámico correspondiente al Período Formativo Final.

Una vez definido el nivel piso y excavados los pisos tanto exterior como interior de los E-A 1 y 2, decidimos concentrarnos en las capas por debajo de este nivel. Por cuestiones de metodología, las denominaciones de las capas siguen la numeración en orden estratigráfico ( $\mathrm{S}, \mathrm{A}, \mathrm{B}$, piso, C). Por esta razón, a la capa debajo del piso del E-A 2 seguimos llamándola Capa C. Mientras tanto, en la parte externa de los E-A 1 y 2, continuamos excavando la Capa C2.

3.2.2.2. Capa C2 (exterior del E-A 2): Es una capa de color beige semicompacta, de granulometría mediana-fina, con abundante presencia de material cultural (carbón, óseo y cerámica). El espesor de la capa oscila entre 50 y 54 centímetros. Al final de esta capa, se definió parte del muro y el nivel de piso del E-A 8. El piso estuvo asociado a cerámica fragmentada y carbón. El material está asociado al Período Formativo Tardío. El nivel de piso del E-A 8 no aparece en toda la unidad 


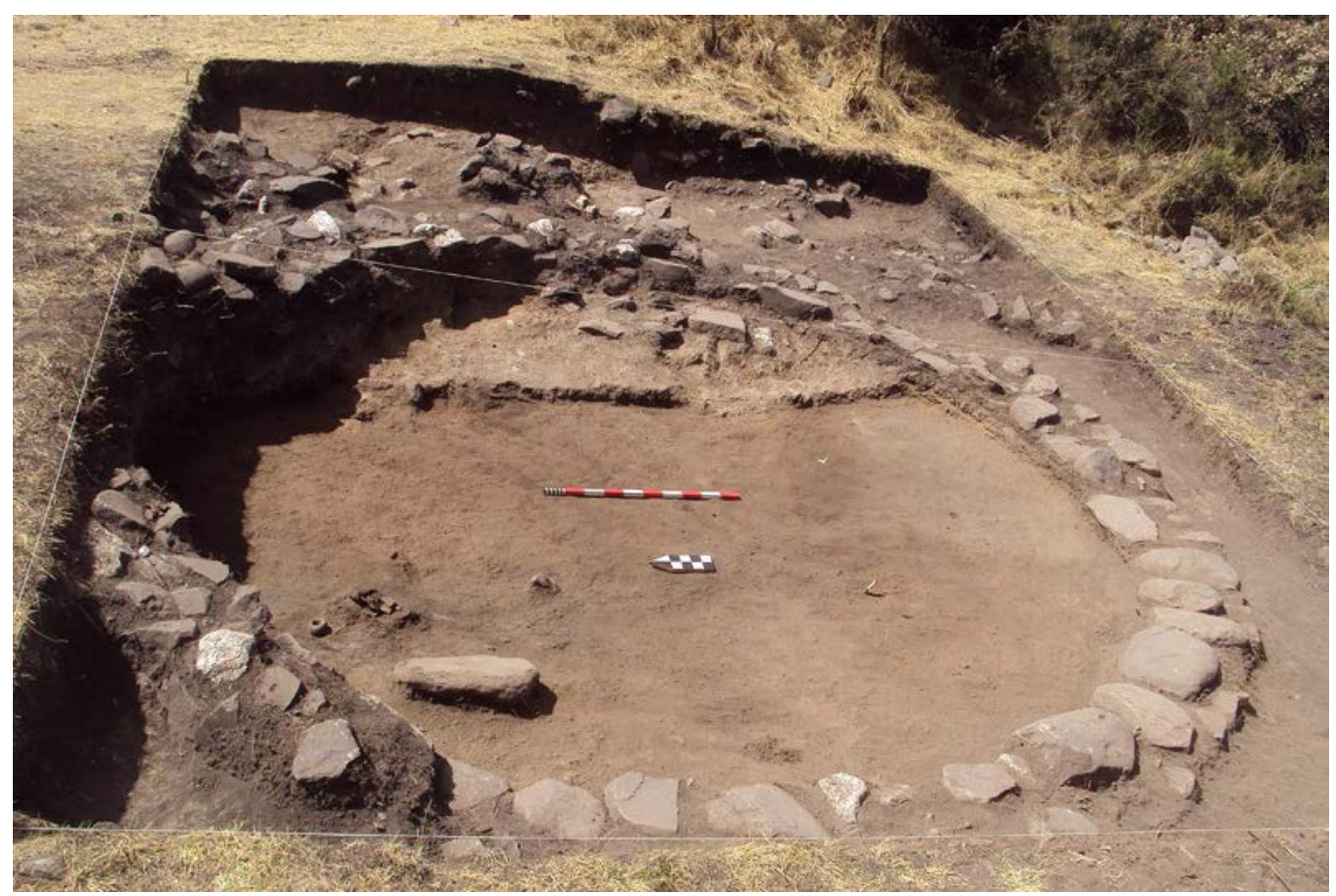

Figura 7. Espacio Arquitectónico $N^{\circ}$ 2. Piso 2, a nivel se observa un mortero invertido y una porra (Foto: Edison Mendoza).

extendida horizontalmente; este se pierde hacia el sur por la diferencia de alturas existentes entre el norte y sur de la unidad.

\subsection{Fase 2 B (interior del E-A 2)}

Al excavar horizontalmente la capa debajo del Piso 2, se definió otro nivel de piso, que guarda relación con el piso del E-A 8.

\subsection{Fase 2A (exterior del E-A 2)}

Al definir la fase $2 \mathrm{~B}$, por debajo de este nivel, se hallaron otras capas de relleno y otros niveles de piso que también tienen material del Período Formativo Tardío. Desde esta parte, por lo complicado de la excavación debido a la presencia de tres espacios arquitectónicos casi juntos, decidimos concéntranos al interior del E-A 2.

\subsubsection{Excavación al interior del E-A 2}

3.4.1.1. Capa C1: Se halla debajo del Piso 2 del E-A 2. Es una capa de tierra de color plomo con presencia de ceniza, carbón y abundante material cultural — como cerámica, líticos y óseos-, de consistencia semisuelts, de granulometría mediana-fina. Cuenta con regular cantidad de piedras de tamaños pequeños y medianos. Probablemente, se trata de basura doméstica relacionada con la preparación y consumo de alimentos. Esta capa tiene un buzamiento de norte a sur. El espesor de la capa oscila entre uno a 140 metros. Por su caracterización, responde a un estrato de relleno. $\mathrm{Al}$ parecer, están nivelando el terreno para construir los E-A 1 y 2 . Debido al espesor de esta capa de más de un metro de altura, esta fue excavada en 11 niveles arbitrarios. Cada uno de los niveles presentó consistencia y color similar. Solo hemos podido aislar por la presencia de unos pequeños lentes de color beige que parecen ser pisos, y están en dirección y a la altura de los niveles de muros. 


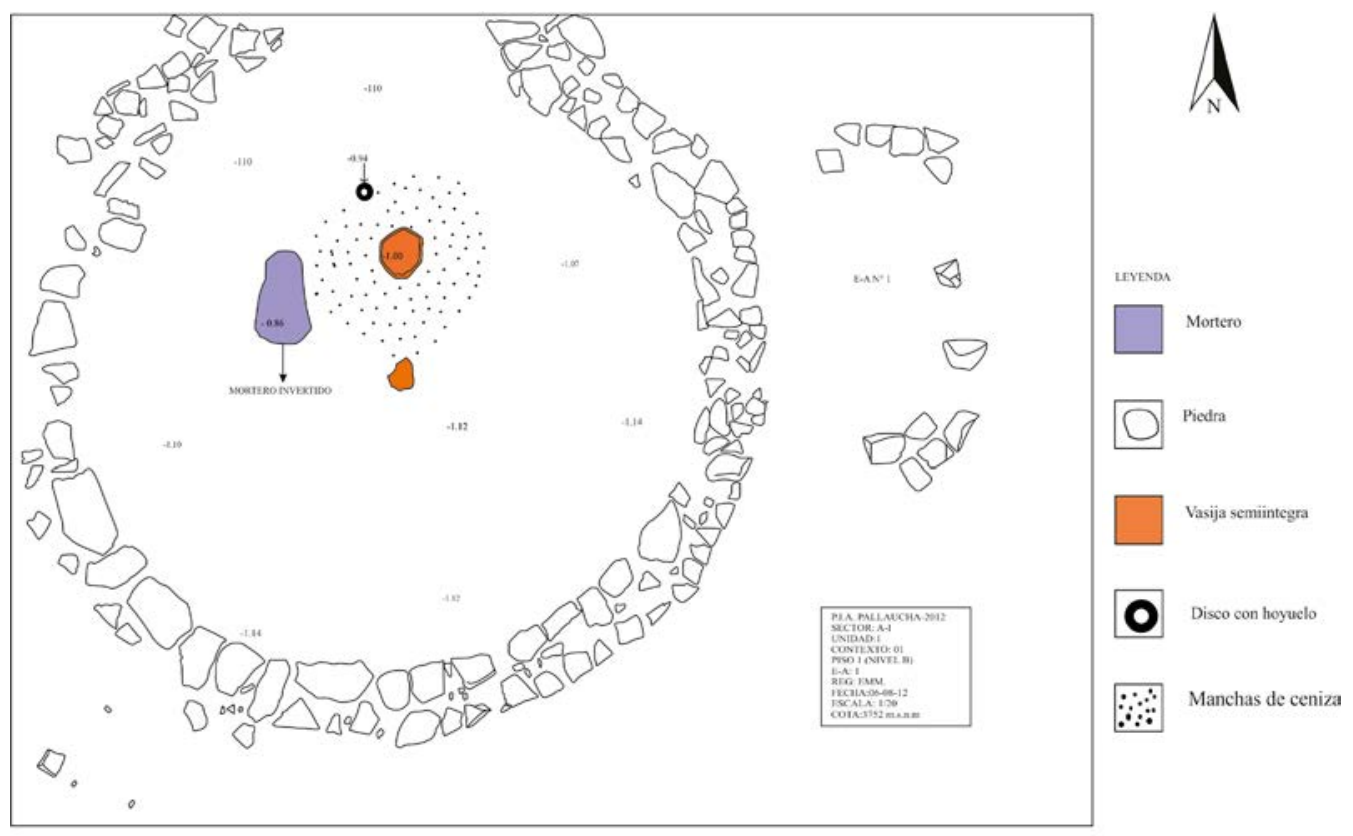

Figura 8. Dibujo de planta final de piso 2 del E-A: 2 (Fase 3) (elaboración: Edison Mendoza).

En los niveles C 3, 4 y 5, se halló regular cantidad de piedras de tamaño pequeño (entre uno y tres centímetros). En los niveles 5, 6 y 7, se definió un nivel de piso que guarda relación con las bases del muro del E-A 3. En este nivel, se observan morteros, batanes, manos de moler, cerámica fragmentada y abundante cantidad de restos de carbón y ceniza. Asimismo, en el sedimento final en el C9, aparece un lente de ceniza que guardaría relación con el piso del E-A 6. Al finalizar la excavación asociada a la C11, encima del suelo estéril, se hallaron restos de morteros, piedras que forman un círculo a manera fogón, lo cual se relaciona con el nivel de piso del E-A 6 (Fig. 9).

Este sedimento, al momento de la excavación, se hallaba bastante húmedo. Tenía una coloración más oscura y, expuesto al sol, adoptó una coloración ploma ahumada. También, se logró diferenciar diferentes tonalidades y texturas, lo que indica deposición de diferentes rellenos $\mathrm{y}$ en tiempos distintos.

3.4.2. Espacio arquitectónico 3. Este se ubica al interior debajo del nivel de piso del E-A 2. Al excavar al interior de este espacio arquitectónico, se definió la Capa C, la misma que se dividió en dos niveles: $\mathrm{C} 1$ y C2. Esta se caracteriza por la presencia de piedras de tamaño pequeño y grande. La capa C1 sella y cubre las cabeceras del muro del E-A 3. Por su parte, la capa C2 básicamente responde a la capa de relleno del interior de E-A 3. Debajo de C2, se definió un piso de color beige con abundante mica y que contenía carbón. Casi al mismo centro del E-A 3, hallamos un mortero que estaba invertido (Fig. 10). Cabe anotar que la capa C1 tiene un espesor que oscila entre los 10 y 15 centímetros; y la C2, entre 50 y 56 centímetros. El material asociado responde al Período Formativo Tardío.

3.4.3. Espacio arquitectónico 7 (Fig. 11). Al interior de este E-A, se definieron las capas $S$, A-1, B-1, 2 y 3 (estos sedimentos responden a capas de rellenos de piedra). Al retirar las capas mencionadas, se encontraron pequeñas lajas pulidas a manera de batanes y manos de moler. En este nivel, no se ubicó ningún piso, solo un relleno suelto como la Capa B, lo que nos hace suponer que al parecer la colocación de estas lajas corresponde al momento de abandono. 


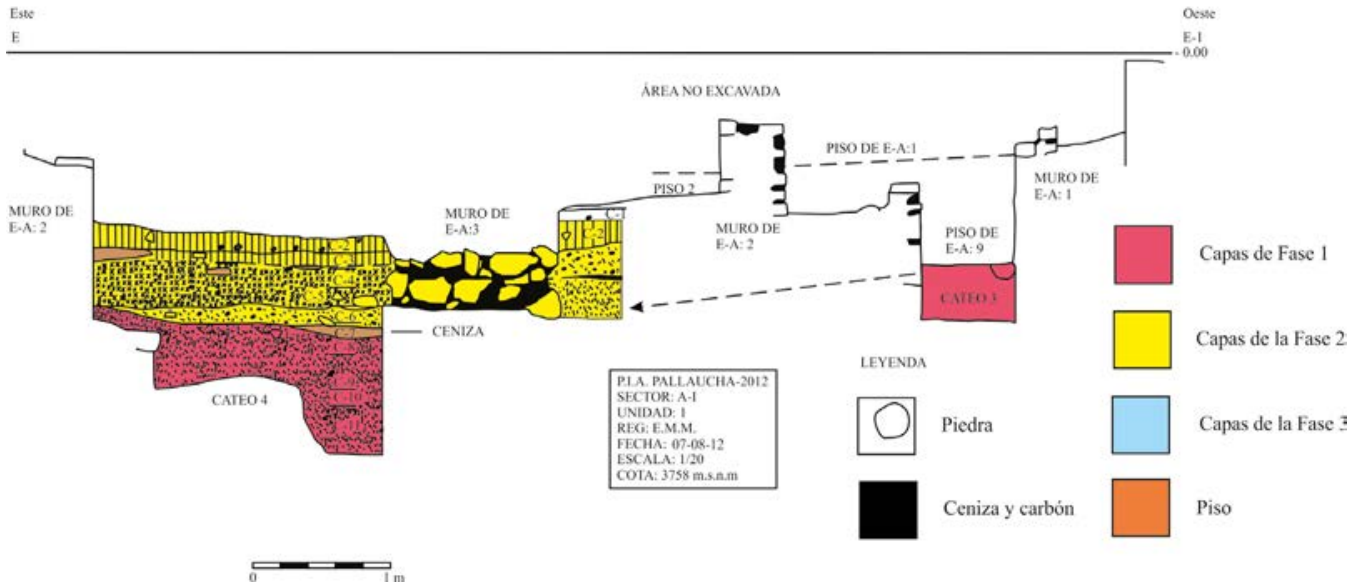

Figura 9. Dibujo de corte perfil central (elaboración: Edison Mendoza).

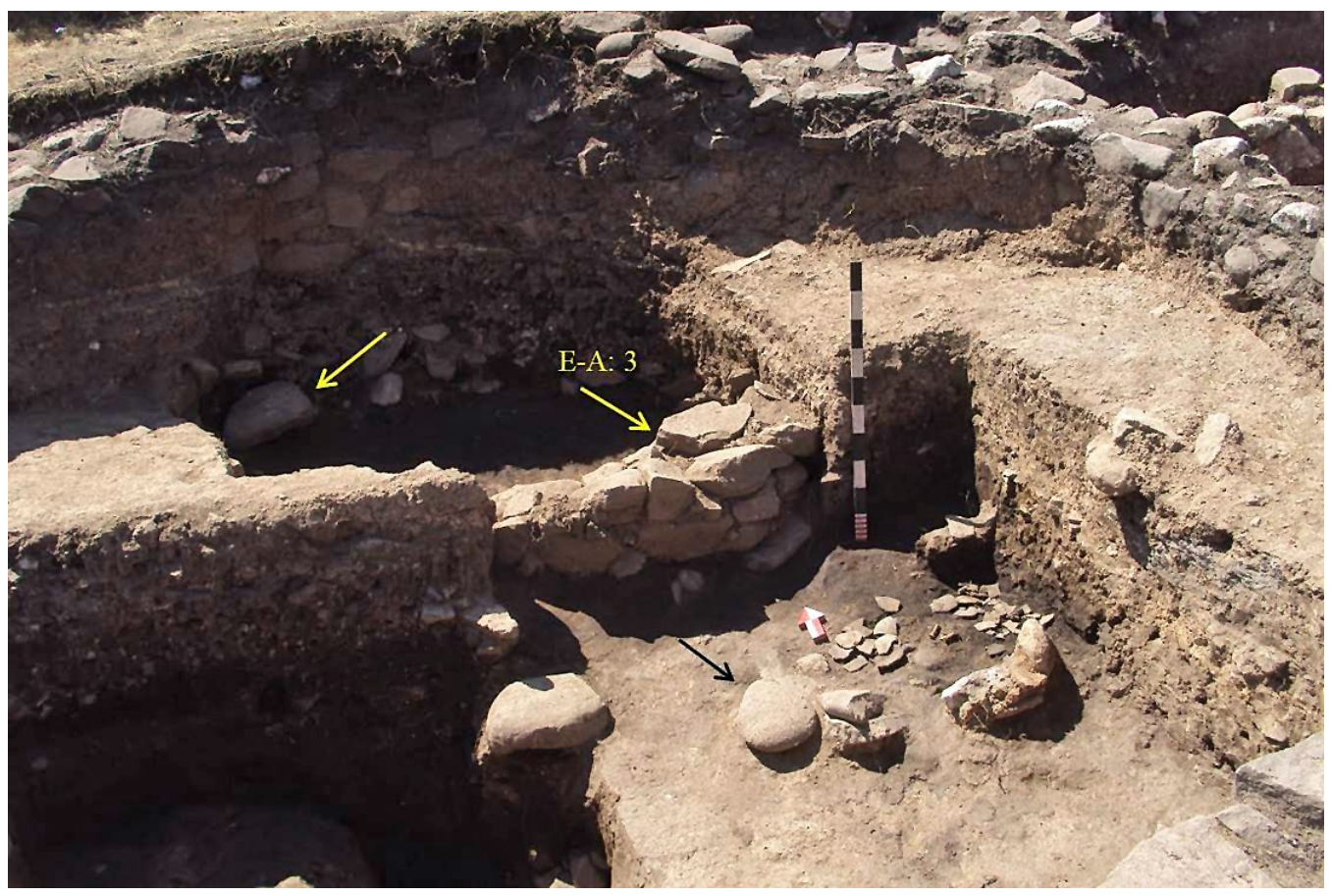

Figura 10. Patio del Espacio Arquitectónico $N^{\circ}$ 3, véase cerámica fragmentada y dos morteros intencionalmente invertidos (en la flecha), uno al interior y otro al exterior del E-A: 3 (foto: Edison Mendoza). 


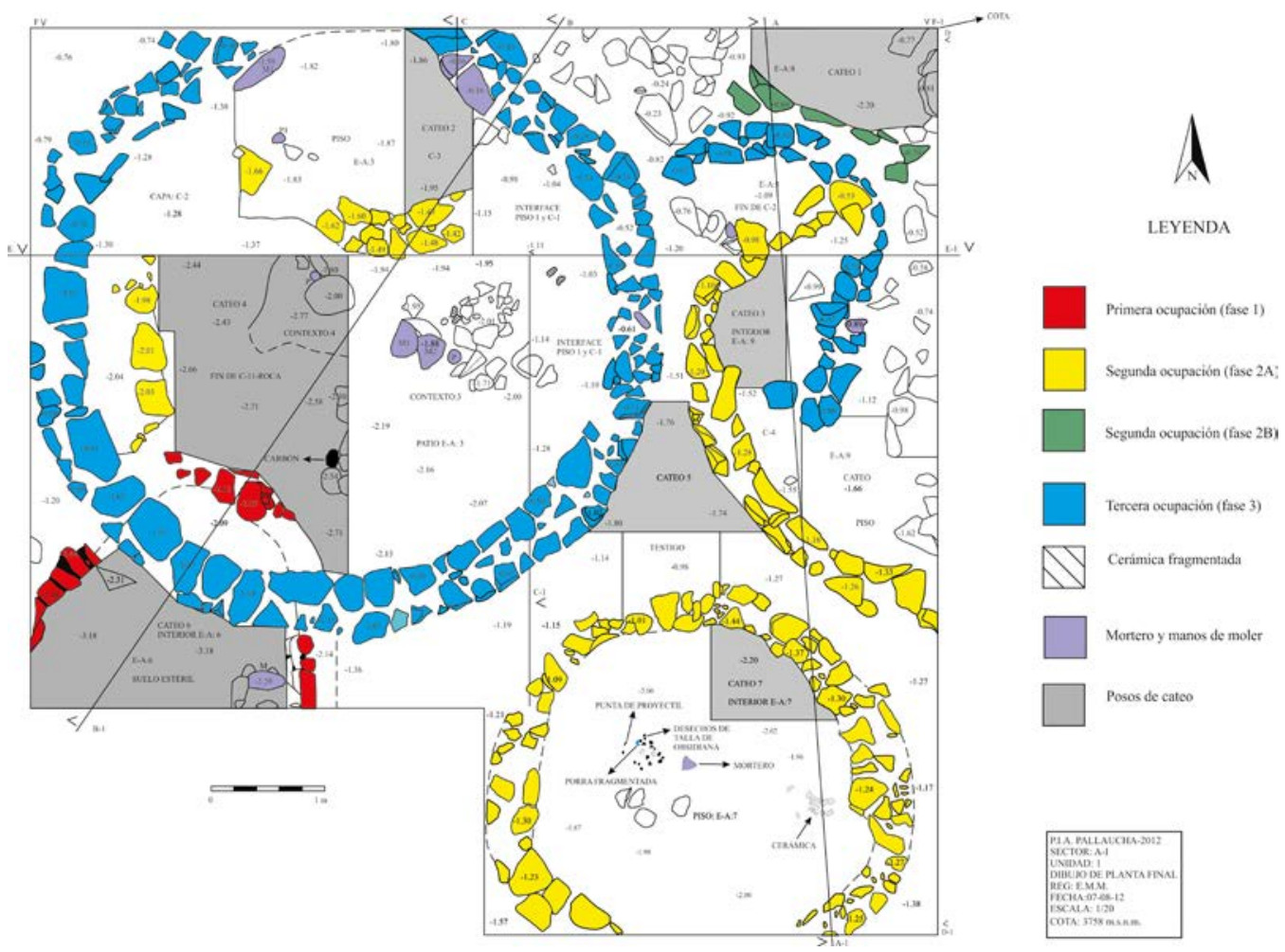

Figura 11. Dibujo de planta final (elaboración: Edison Mendoza).

Luego de retirar las capas antes descritas, se definió un piso de color beige, sobre el cual se hallaron dos contextos. Uno de ellos se compone de cerámica fragmentada; y el segundo, de desechos de talla de obsidiana, pequeños nódulos de obsidiana, un mortero fragmentado y una macana (porra) elaborada de una piedra especial. El material asociado responde al Período Formativo Final. Al parecer, es una estructura construida durante el Período Formativo Tardío (fase 2 A) y reutilizada durante la fase 3, puesto que se encontró una cerámica con diseños de felino; sin embargo, los niveles de piso guardan relación más o menos horizontal con el piso del E-A 3.

Debajo del piso, se registraron las capas C1, D1 y D2, asociada al Período Formativo Tardío, fase 1. Al excavar los depósitos mencionados, no se pudo definir el acceso a la estructura; solo se identificó un muro, el cual al parecer se utilizó para tapiar el ingreso. Así también, en el nivel de piso de los E-A 3 y 7, se ha definido el E-A 9.

3.4.4. Espacio arquitectónico 9 (Fig. 11). Al interior de esta estructura, se definieron tres niveles: C2, C3 y C4. Debajo de las capas mencionadas, se expuso un piso de lajas.

\subsection{Fase 1}

Corresponde al primer momento de ocupación del sitio, continuando la excavación debajo de los niveles de piso de los E-As: 3, 7 y 9 se halló otra estructura el E-A: 6.

3.5.1. Espacio arquitectónico 6 (Figs. 12 y 13). Está cubierto por el piso del E-A: 3, su nivel de piso se asocia con el inicio del nivel -9 (interior E-A 2). En el nivel C9, se registraron gran cantidad 


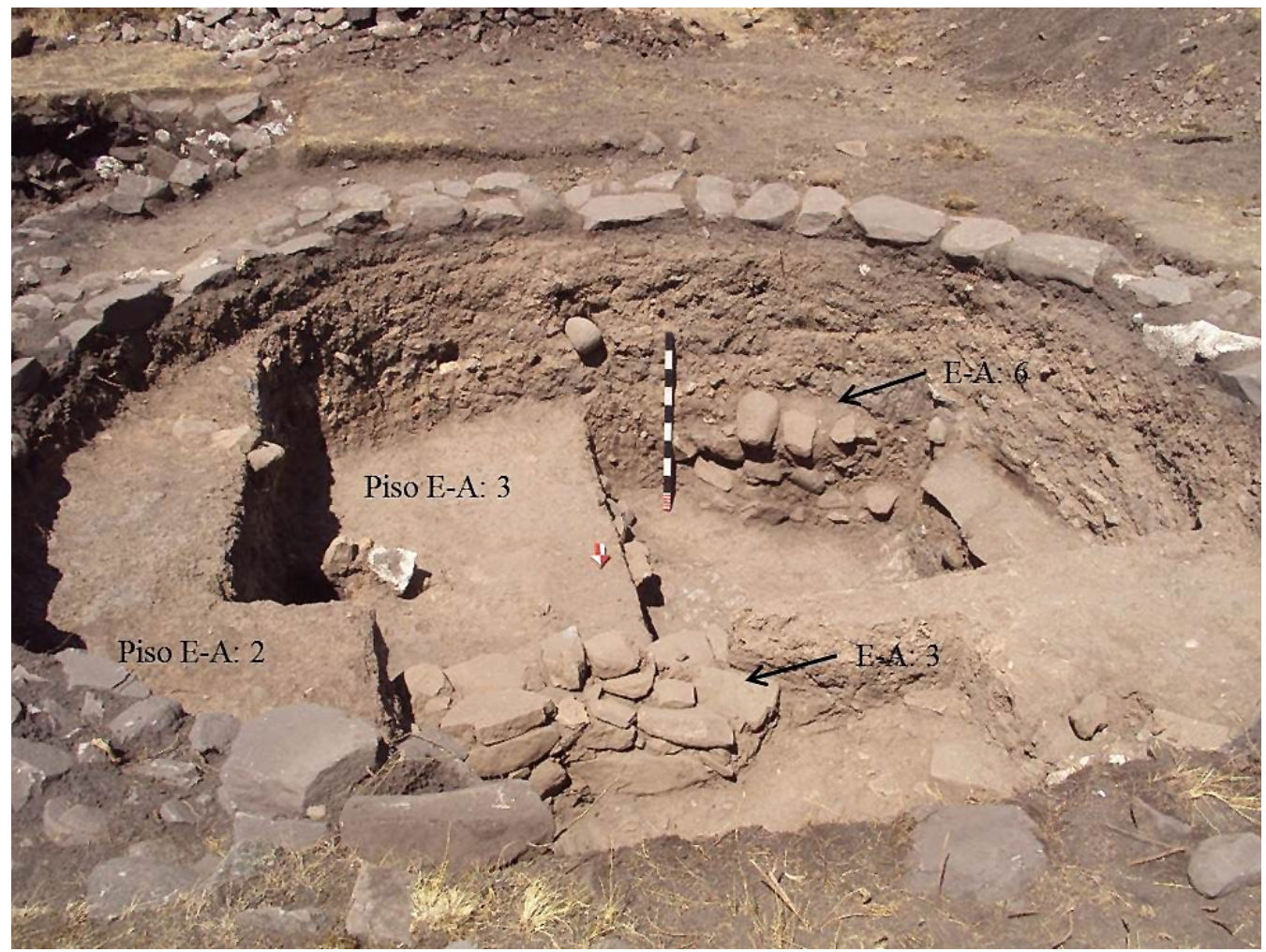

Figura 12. Final de excavación de la unidad $N^{\circ} 1$. Detalle de la superposición de los E-As: 6, 3 y 2.cada nivel estás asociado a un piso de ocupación. Los E-As: 6 y 3 están asociados al Formativo Tardio y el E-A: 2 al Formativo Final (foto: Edison Mendoza).

de piedras de tamańo mediano como relleno; al parecer, esto responde al momento de abandono. Asimismo, hallamos un mortero invertido.

El nivel C-11 se halla debajo de la arquitectura encima de la roca. En este, no hallamos cerámica, pero sí carbón.

\subsection{Resumen}

La sucesión arquitectónica estuvo acompañada de sellos y rellenos de las fases arquitectónicas anteriores. En el perfil de la fase 2, se pueden diferenciar dos lentes de color beige que están relacionados con dos pisos de ocupación. El material cultural al interior de estos dos pisos son similares. La diferencia consiste básicamente en las sucesiones arquitectónicas. Además, se debe advertir que los sedimentos no se disponen de forma horizontal, sino que existen hoyos que alteran las capas anteriores. Todo ello exige definir materiales culturales asociados a los pisos.

\section{Análisis del material cerámico paracas en Pallaucha}

Para el análisis de material cultural, principalmente, consideraremos los materiales culturales paracas. No describiremos otros componentes culturales; solo lo mencionaremos. Contamos con 19 tiestos decorados (Fig. 14). 


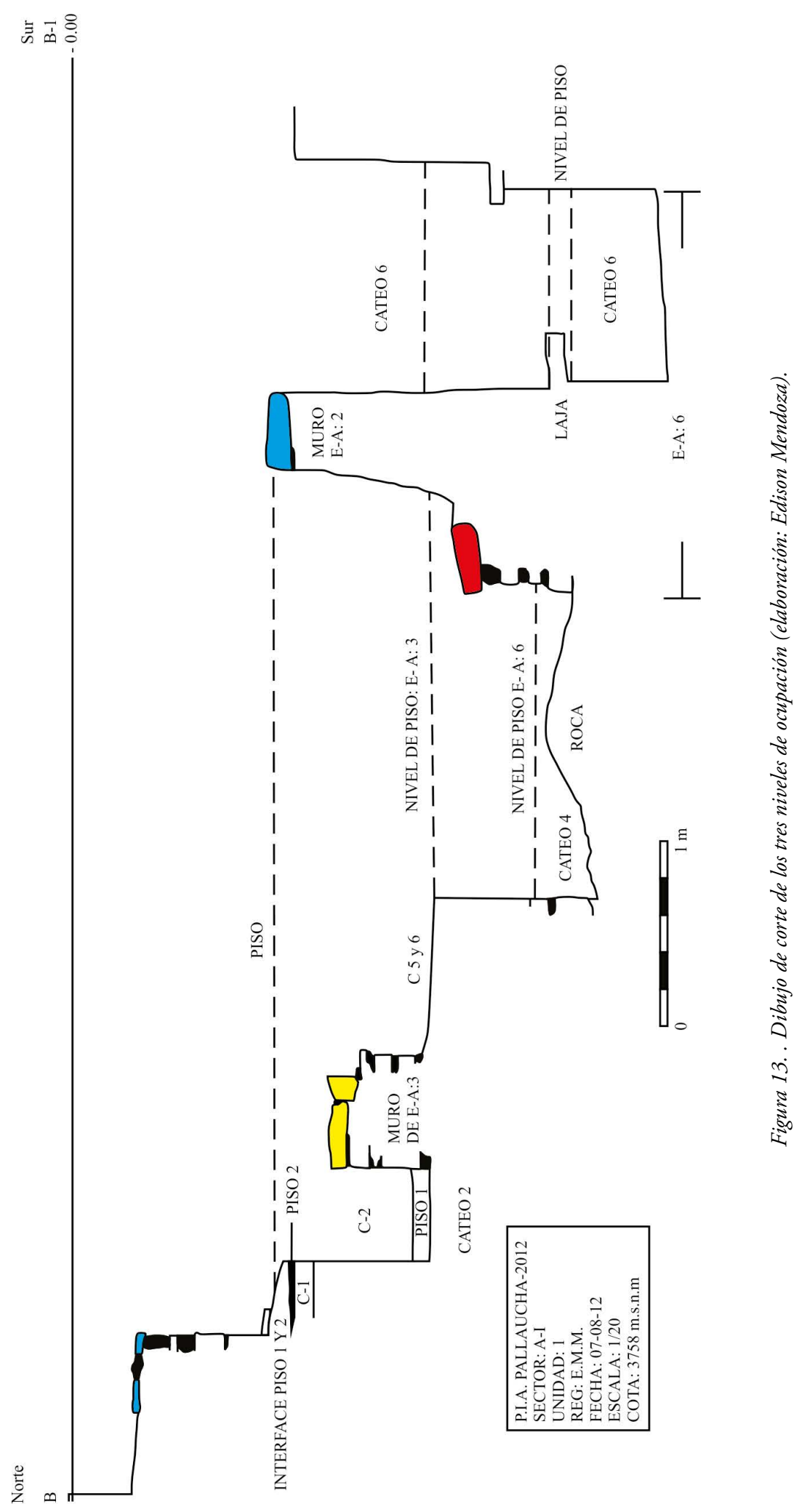




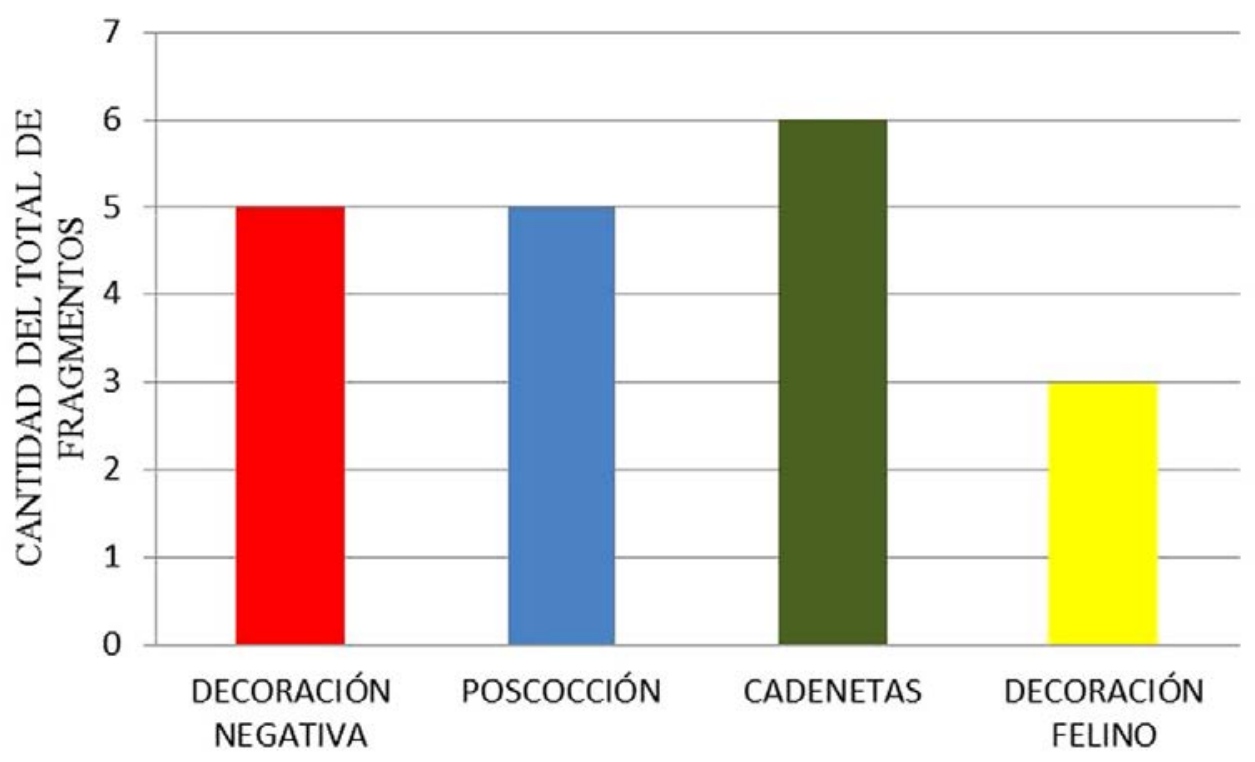

Figura 14. Gráfico de la cerámica Paracas hallada en Pallaucha (elaboración: Edison Mendoza).

\subsection{Período Formativo Tardío (Fase 1)}

Esta fase está asociada a una cerámica conocida como janabarriu. Junto a esta, se halla la cerámica con decoración negativa paracas.

4.1.1. Decoración negativa (Fig. 15). Las vajillas de este grupo, como decoración, presentan dos colores marrón y rojo. La base es de color rojo (5YR 7/6 - 5YR 6/6) y, sobre esta, se halla la decoración marrón (7YR 5/4). Como diseño, resaltan los puntos, los círculos con puntos internos y las franjas en zigzag. Todos los tiestos en el exterior tienen un acabado pulido con brillo y suave al tacto, aunque en el interior solamente se hallan en tres de ellos (Figs. 15a, 15b y 15c). Los otros presentan acabados del tipo alisado sin engobe. Tienen una superficie bastante homogénea y el espesor de los tiestos oscila entre los 0,4 a los 0,7 milímetros.

El fragmento (Fig. 15f) tiene los mismos colores que los primeros; sin embargo, en este caso, el borde de los diseños es irregular (como si se hubiese hecho sin tener cuidado). Asimismo, la pasta es diferente, con mayor cantidad de mica (pasta B). Al parecer, responden a una manufactura local. Su acabado es más tosco; también, su espesor es más ancho que 0,8 milímetros.

Todos los fragmentos por la coloración de pasta responden a la atmosfera oxidante, con fractura irregular, a excepción del fragmento $B$, que tiene una fractura ligeramente recta, pasta de color anaranjado sin defecto de cocción, con escaso feldespato (pasta A).

\subsection{Período Formativo Tardío (Fase 2)}

En esta fase, desaparece la cerámica janabariu y la cerámica con decoración negativa, y aparece otra con pintura poscocción.

4.2.1. Pintura poscocción (Fig. 16). Las vasijas de este estilo se caracterizan por presentar líneas incisas en pasta húmeda de uno a dos milímetros. Estas líneas no son continuas sino discontinuas cortantes; es decir, los trazos no son continuos: termina una línea y se inicia otra. Como muestra de ello, al final de cada línea, se observan restos de arcilla. Por sus formas, estas líneas pueden haberse realizado con un instrumento delgado de punta circular. 

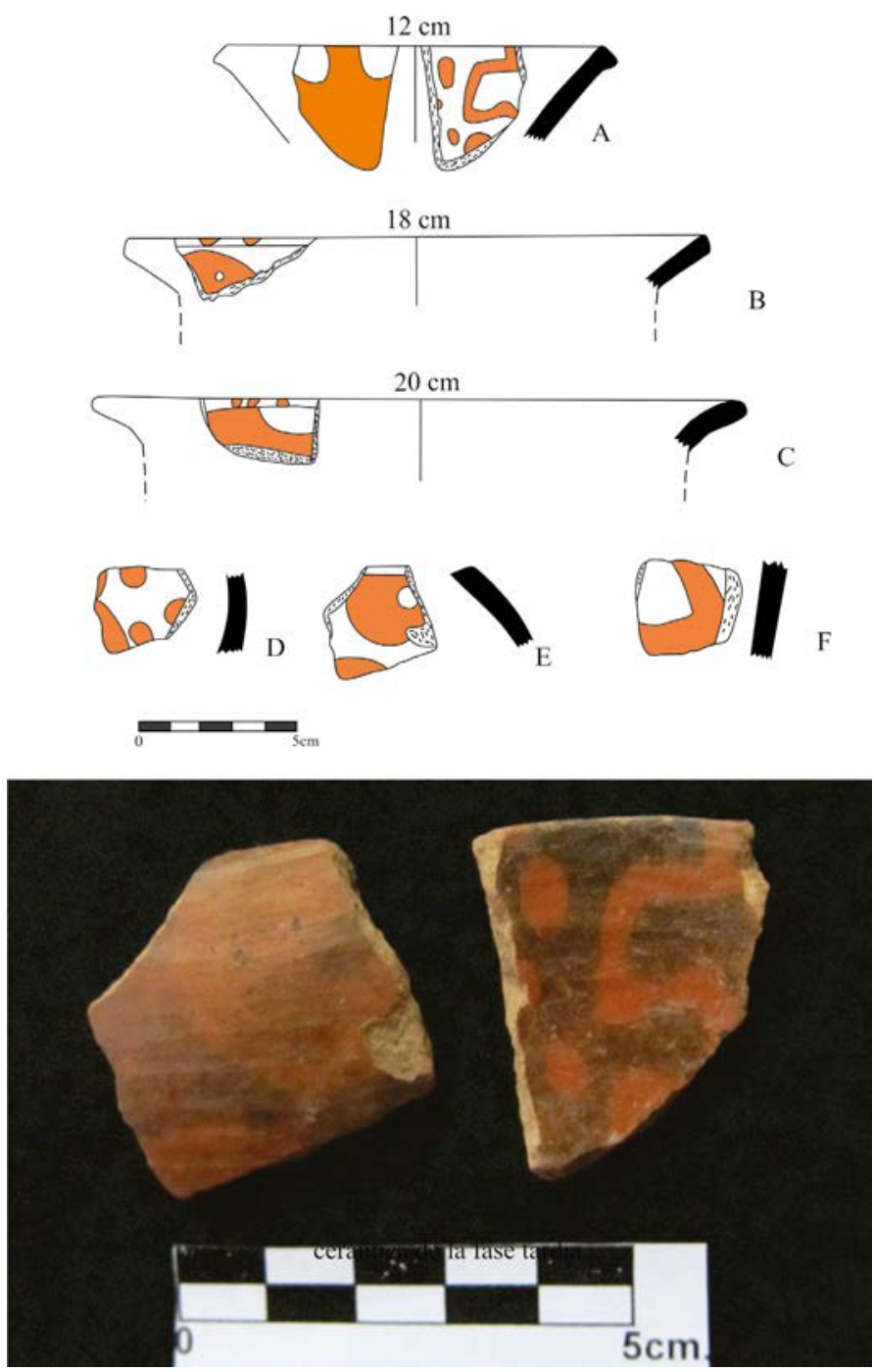

Figura 15. Cerámica Paracas con decoración negativa (Fase 1) (elaboración: Edison Mendoza).

Hemos distinguido tres diseños: i) incisiones dispuestas en forma cuadriculada, que, en algunos casos, pueden ser reticuladas y, en otros, organizan figuras, cuyas dimensiones son de 0,5 a 1,02 centímetros (B, D y E); ii) incisiones de formas curvadas (Fig. 16c); iii) incisiones rectas en zigzag, a las que se asocian estampados circulares con diámetros de 0,9 milímetros (Fig. 16a). Entre estas incisiones, se observan decoración poscocción alternados con color blanco (10R 8/1) y rojo (10R 4/6 - 10R 6/8).

El espesor de los tiestos tiene una superficie casi homogénea, que oscila de 0,4 a 0,6 milímetros, mientras que la fractura de la pasta es irregular. En la parte interna, todas las vajillas tienen un buen acabado, pulido y con brillo. En las vajillas (Figs. 16b, 16c y 16e), se observa el acabado de tipo alisado con trapo, mientras en la Figura 16A, es casi invisible, puesto que se trata de un plato. En el caso de la vasija (Fig. 16d), en el interior, no se observa engobe ni pulimento. Finalmente, cabe anotar que todos los tiestos tienen el mismo tipo de pasta A con feldespato, a excepción de la Figura 16d, en la que se observa la pasta $B$ con abundante mica. 

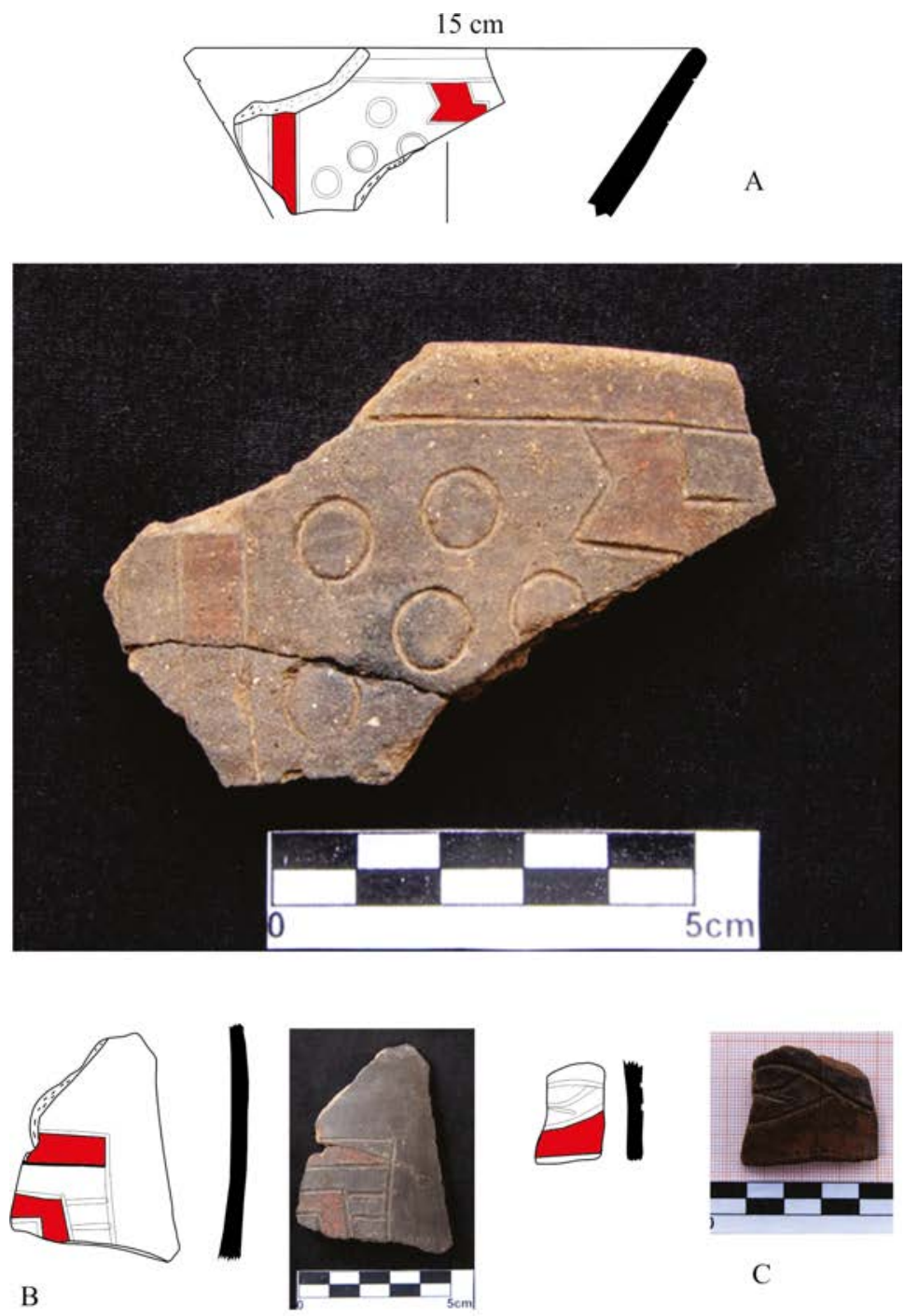

C
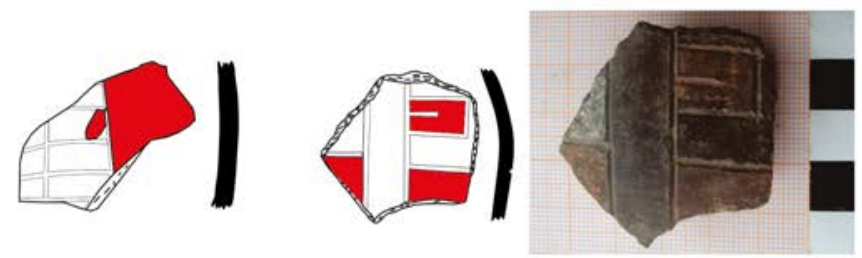

D

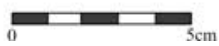

E

Figura 16. Cerámica Paracas poscocción (fase 2) (elaboración: Edison Mendoza). 


\subsection{Período Formativo Final (Fase 3)}

En esta fase, hay ausencia de los elementos culturales anteriores, y aparecen alfares con diseños de cadenetas y con decoración de felino.

\subsubsection{Decoración incisa de cadenetas (Fig. 17)}

4.3.1.1. Fig. A: Se trata de una taza, con diseño de cadenetas a la altura del borde. Estos diseños fueron realizados con líneas incisas cortantes en pasta húmeda con un milímetro de ancho. Estas cadenetas forman áreas circulares alargadas de 1,5 a 1,6 centímetros de ancho, mientras que la franjas entre las dos líneas de cadenetas oscilan entre los 0,5 y 0,7 milímetros. El diseño de las circunferencias es bastante irregular, por lo cual es probable que estas se hayan hecho a mano alzada. En la parte central de estas, se observan círculos incisos de 0,6 milímetros, cuyo tamaño de es homogéneo, como si se hubiera hecho con una caña. Estas líneas incisas también se disponen de forma horizontal y vertical formando un rectángulo, el mismo que rodea a las cadenetas. En cuanto al acabado, este es bastante homogéneo. El espesor del tiesto oscila de 0,5 y 0,7 milímetros. Con respecto a su morfología, resalta un cuerpo central más ancho; este se reduce a la base y al borde. Además, la taza tiene una fractura ligeramente irregular. Los tiestos se hallan bastante erosionados y son toscos al tacto. En cuanto al engobe observado, es de color naranja. Finalmente, se debe ańadir que la pasta presenta defecto de cocción; en el corte, los lados externos evidencian franjas delgadas de color beige y, en el interior, plomas.

\subsubsection{Decoración incisa con motivo felínico (Fig. 18)}

La pasta es similar a las vajillas de los grupos B, C, D y E.

4.3.2.1. Fig. $A$, $B$ y $C$ : Se trata de una vajilla abierta con diseños incisos en el interior. Los diseños consisten en líneas incisas rectas y curvilíneas hechas a mano alzada con instrumento punzante; en la mayoría de los casos, son franjas paralelas. Estas líneas también son cortantes; es decir, cada línea incisa es independiente. Las mismas forman espacios triangulares y rectangulares. También, hay círculos estampados realizados con caña. El tiesto en su superficie es bastante homogéneo y el espesor oscila entre 0,3 y 0,4 milímetros.

En su superficie, se observan pequeños poros como evidencia del uso de materia orgánica. En relación con ello, se debe acotar que la arcilla no fue bien preparada. Sobre el engobe, tiene acabado interno con engobe de color rojizo (2YR 5/8) sobre una pasta beige, mientras que, en el exterior, no presenta engobe; al contrario, es oscura sin engobe. El tipo de pasta es similar a los tiestos con decoración de cadenetas.

\section{Resumen de secuencia estratigráfica de la Unidad 1}

En esta unidad, se han definido cuatro secuencias arquitectónicas de estructuras circulares y se agrupa el material cultural en tres fases. Las tres primeras fases arquitectónicas y dos de cerámica responden al Período Formativo Tardío, y una fase de arquitectura y una de cerámica responden al Período Formativo Final.

La fase 1 responde a la ocupación más antigua del sitio asociado a la cerámica con círculo punto conocido como Janabarriu y a la cerámica con decoración negativa (Ocucaje 4 y 5), asociada al E-A 6 (Fig. 15). Por su parte, la fase 2 se ha subdividido en dos (A y B) a partir de las secuencias arquitectónicas $2 \mathrm{~A}$ (E-A 3, 7 y 9) y 2B (E-A 8). A diferencia de la primera fase, no existe mucha variación del material cultural; la cerámica asociada responde principalmente a materiales de la costa sur cerámica poscocción (Ocucaje 4 y 5). Desaparece la cerámica janabarriu y la cerámica con decoración negativa. Finalmente, la fase 3 está asociada a la cerámica ocucaje de las fases $(6,7$ y 8$)$, contemporánea con la fase Chupas (Lumbreras 1974). 


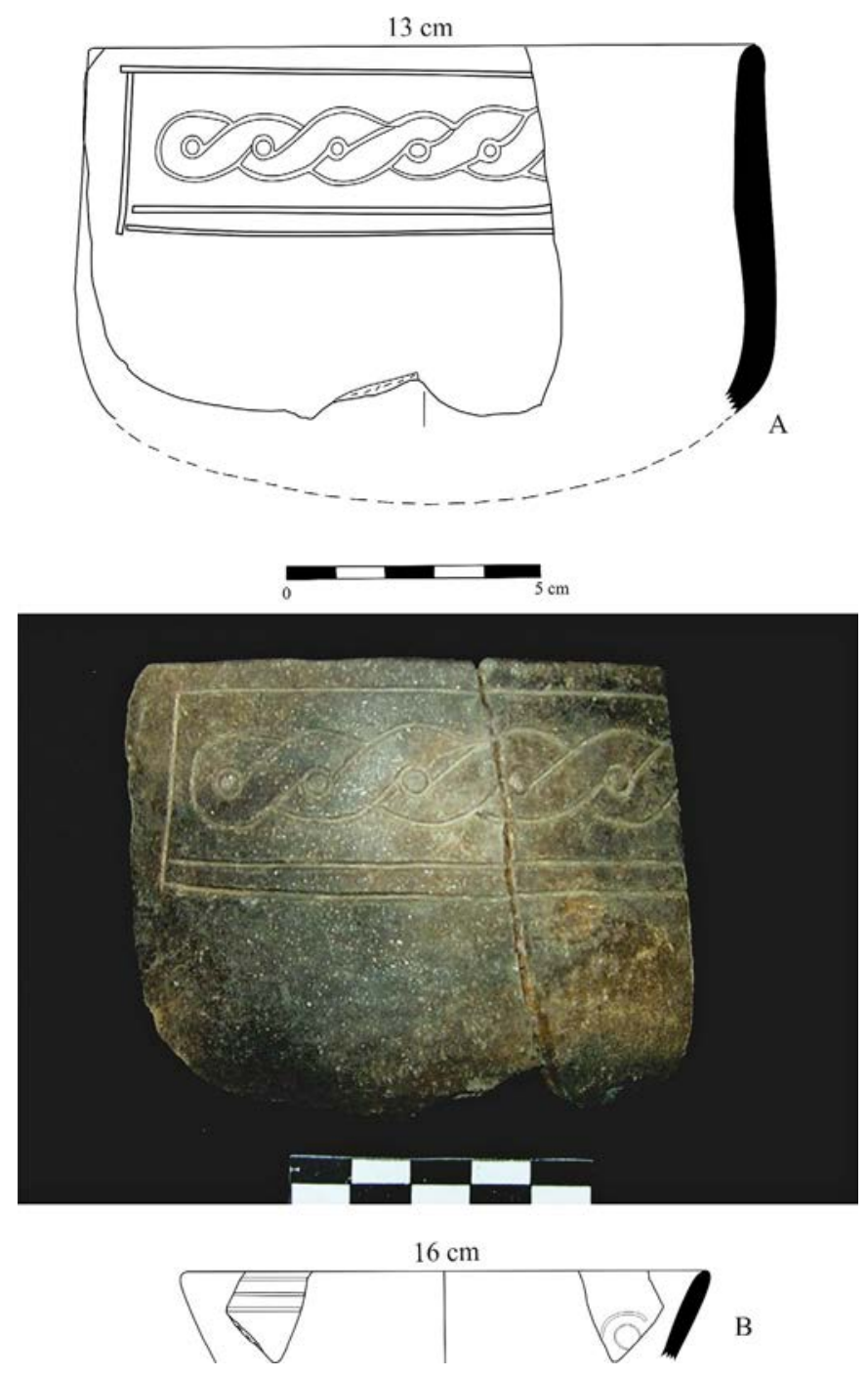

Figura 17. Vajillas con incisión de tipo cadenetas (Fase 3) (elaboración: Edison Mendoza).

Finalmente, es de mencionar en todas estas fases hay una cerámica muy popular, a la que estamos denominando estilo Pampas. Esta se caracteriza por una cerámica de pasta semicompacta, con abundante mica (pasta B). La cerámica es brillosa, con acabado de alisado simple. Resalta la decoración de puntos y líneas hechos con punzones; algunos se asemejan a la cerámica tajo (Fig. 19).

\section{Presencia paracas en Ayacucho}

La aparición de la cerámica en la región de Ayacucho es muy problemática. Los reportes de MacNeish se concentran en los inicios del Período Formativo Temprano; los mismos fueron asociados con la cerámica andamarca, seguidos de otros del Período Formativo Medio, como el estilo Wichqana. A ambos estilos MacNeish (1981: 223) los asocia con la fase Andamarca. En la actualidad, Andamarca es el estilo menos conocido y poco mencionado en la literatura del Período Formativo en Ayacucho. 


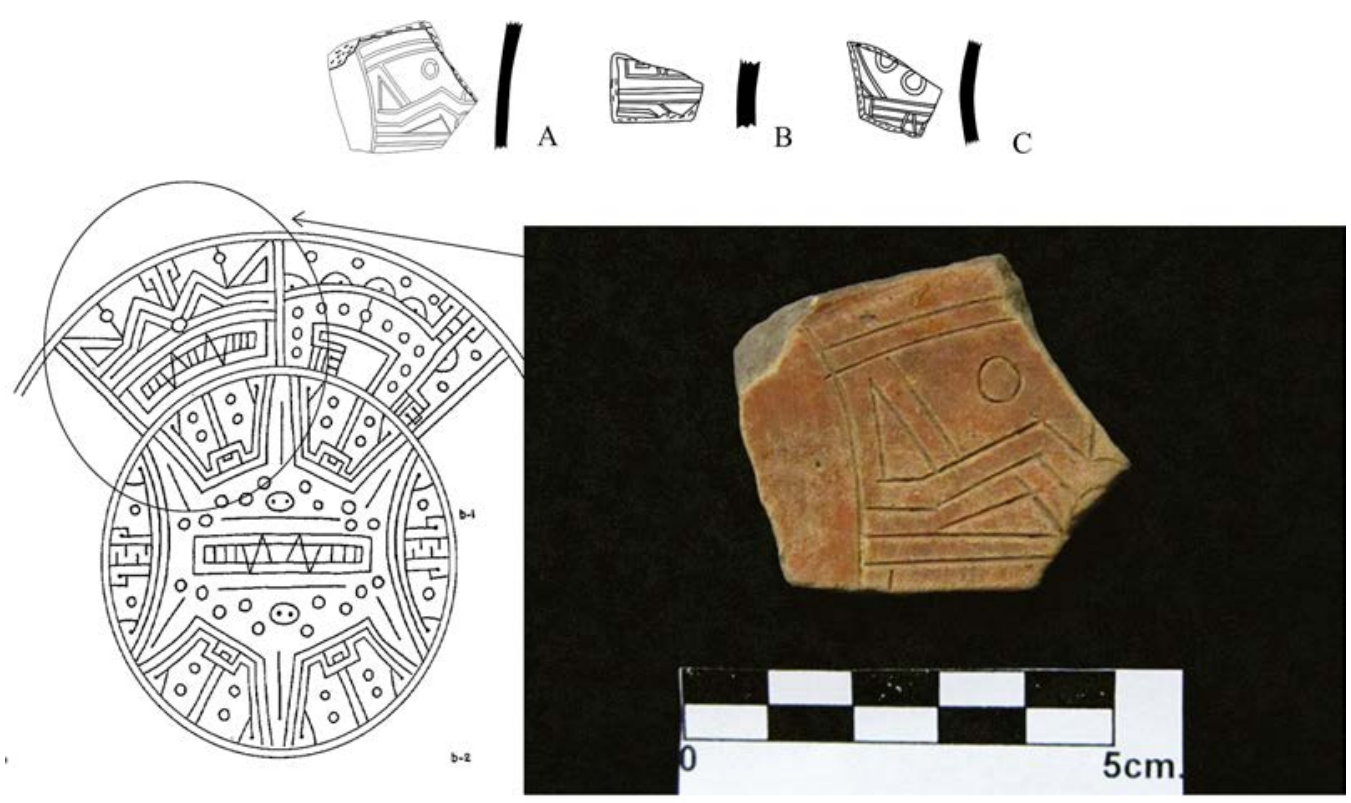

Menzel et. al (1964: 363. Fig. 45 b. fase 8. Callango).

Figura 18. Vajillas con decoración incisa, cabeza de felino (elaboración: Edison Mendoza).

$\mathrm{Al}$ respecto, Lumbreras señala: «De la cerámica Andamarca apenas tenemos unos pocos ejemplares; el tipo dominante es una cerámica anaranjada muy bien lograda a través de hornos con oxigenación; la cerámica es compacta y en algunos casos muestra pintura roja en bandas sobre una superficie pulida. Pudiera tener alguna relación con una cerámica similar de la costa central» (1974: 75). Tanto en los sitios de Chupas como en Wichqana esta cerámica apareció debajo de la primera estructura o, al menos, parece no estar conectada con estructura alguna, pero existen niveles de pisos superpuestos (Cruzatt 1971: 626; Lumbreras 1974: 75). La datación sugiere un lapso de tiempo entre 1750 a 1250 a.C. (MacNeish 1981: 223). Definir esta fase temprana es muy complicado, puesto que no se tienen elementos asociados claros como arquitectura; debajo de estos, no se ha podido determinar con precisión la transición del Período Arcaico al Período Formativo. Casos similares ocurren en otros sitios, como Campanayuq Rumi (Matsumoto y Cavero 2009: 342).

La arquitectura monumental temprana del Período Formativo para Ayacucho recién aparece a finales del Período Formativo Medio definido para el sitio de Campanayuq Rumi, (Campanayuq I, 950-700 a 500 a.C. [calib.]). El sitio tiene la configuración en forma de «U». En esta fase, se erigieron, por lo menos, tres grandes plataformas y la Plaza Central. Aquí se da la disposición de los elementos arquitectónicos en forma de «U». Las características de la cerámica apuntan a un vínculo con complejos de la sierra centro-sur y costa sur, como Waywaka, en Andahuaylas; Marcavalle, en el Cuzco; la fase Pirwapukio de la cuenca del Mantaro; y Hacha, del valle de Acarí (Matsumoto y Cavero 2009: 342). Estos datos sugieren la importancia de Ayacucho durante el Período Formativo. Así también, hay presencia temprana de materiales de la costa sur. Hasta la actualidad, fuera de Campanayuq Rumi, no se ha reportado materiales paracas de esta fase temprana; sin embargo, existen amplios reportes para las fases tardías. En ese sentido, probablemente, la ausencia de materiales paracas responde a los pocos trabajos efectuados en el área.

Más tarde, para el mismo sitio, se define la fase Campanayuq II (700 - 500 a 450 a.C. [calib.]). Esta se caracteriza no solo por el cambio radical en el estilo cerámico, sino también por las nuevas actividades constructivas de adición y modificación de la arquitectura de la fase Campanayuq I. 


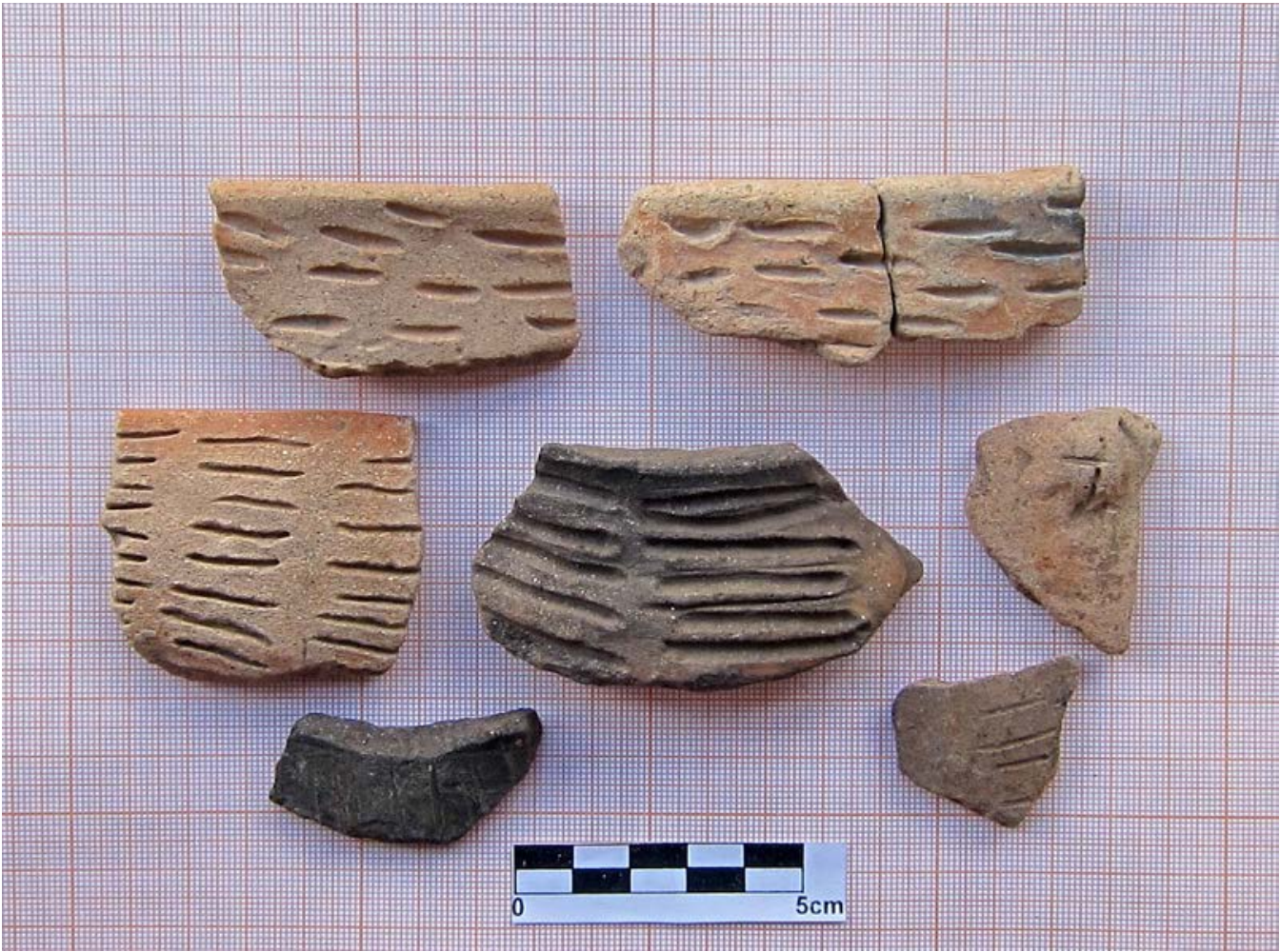

Figura 19. Cerámica de tradición local, estilo Pampas, se halla en todas las fases de Pallaucha (1, 2 y 3) (foto: Edison Mendoza).

Los elementos del Cuzco, Andahuaylas y el valle de Acarí que existían en la fase anterior desaparecieron y fueron sustituidos por otro estilo cerámico. Las características de la cerámica de la fase Campanayuq II indican un vínculo estrecho con la fase Janabarriu de Chavín de Huántar; la fase Cerrillos del sitio de Cerrillos, en el valle medio de Ica; Mollake Chico, en Palpa; las fases Ocucaje 3 y 4; y el tipo Kichka-pata de Ayacucho. (Matsumoto y Cavero 2009: 342). Esta fase es contemporánea a la fase 1 de Pallaucha. Cabe anotar que no existen reportes de esta fase en otros sitios, pero sí para el Período Formativo Final.

Podemos igualmente resaltar a los sitios de Wichqana y Chupas, en la medida que la cerámica paracas en ambos está emparentada con el estilo cerámico llamado Chupas (Cruzatt 1971: 628; Lumbreras 1974: 78), asociado al Período Formativo Superior en la cronología de Lumbreras (1974: 47) o el Período Formativo Final en la de Kaulicke (2010), no se ha encontrado material cerámico Paracas del Periodo Formativo Medio y Tardío. A continuación, describiremos ambos sitios.

El sitio de Wichqana tiene un recinto en forma de «U» o un patio hundido. Su templo temprano está construido con lajas de piedra que fueron dispuestas de «cabeza» sobre el piso; el paramento está construido con las caras planas de piedras colocadas unas al lado de otras, unidas con tierra por los cantos. El templo tardío fue construido en varias épocas, de las cuales las dos primeras siguen básicamente el plan del viejo templo, mientras que la última adopta una tendencia curvilínea (Lumbreras 1974: 60; Pozzi-Escot y Cardoza 1986: 70). Los materiales culturales permiten asociar a cinco fases culturales del más temprano al más tardío: Andamarka (zona M1-K), Wichqana (zona J-G), Chupas (zona F-D), Rancha (zona C) y Huarpa-Rancha (zonas A y B). (Lumbreras 1981: 175 y 177 [traducción del autor]). La transición de la fase Wichqana a Chupas estuvo asociada a los tipos de cerámica Wichqana, Kichkapata y Chupas. Se dispone de un fechado 14 C entre 795 a 605 A.C. (S-598) años radiocarbónicos. Encima de esta capa, aparece otro piso en la zona E. Los pocos restos 
culturales hallados fueron del tipo Chupas, con fechados de 900 a 500 A.C. en años radiocarbónicos (Lumbreras 1981: 174 [Traducción del autor]). Los mismos guardan estrecha relación con la cronología de Kaulicke (2010: 400) de 800-600/500 a.C. para el Formativo Tardío. Posteriormente, en 1974, sobre este mismo sitio, Lumbreras señala lo siguiente: «[...] la capa $\mathrm{H}$ está debajo de la estructura del más viejo edificio y en consecuencia, probablemente asociada a un edificio que no conocemos, obviamente de mayor antigüedad aunque de previsible similitud [...] Por la asociaciones con la cerámica, correspondería al periodo llamado Kichkapata, de neto carácter Chavinoide, mientras que los edificios superiores parecen estar asociados a los periodos Chupas y Rancha [...]» (1974: 59). A partir de la lectura, podemos señalar que Lumbreras modifica el nombre de sus fases: cambia de la fase Chupas a Kichkapata para el Período Formativo Tardío y coloca Chupas junto a Rancha en el Período Formativo Final, a menos que la fase Chupas inicie durante el Período Formativo Tardío como en Campanayuq Rumi; no obstante, en su texto, esto no queda claro.

Por otro lado, en el sitio de Chupas, se observan tres montículos alineados en eje de sur a norte. Las investigaciones se han concentrado en el montículo central. El montículo central trata de una plataforma construida encima de un promontorio rocoso. Este mismo fue rodeado por muros de forma casi subrectangular o rectangular con esquinas circulares, con relleno interno. El eje largo de la pirámide fue casi de suroeste a sureste. Creemos que la parte superior de la plataforma estaba cubierta con tierra; no hemos encontrado empedrado. En su etapa final, esta fue casi 65 metros de largo, 60 metros de ancho (Lumbreras 1981: 178 [traducción del autor]).

Se observa, por la excavaciones practicada por Cruzatt, que el edificio fue replanteado en varias oportunidades, de modo que hay al menos tres estructuras superpuestas: la más antigua corresponde al núcleo central del montículo y tiene unas escalinatas que penetran al edificio, el muro que delimita la plataforma está construido con piedras irregulares de unos $40 \mathrm{cms}$. de alto promedio [...] El muro está a unos $3 \mathrm{mts}$. del anterior, del cual está separado por un relleno similar al que constituye el núcleo del montículo; este relleno cubría, además, las escalinatas de la estructura de piedras irregulares más pequeñas que penetraba en el núcleo de la plataforma. Finalmente, una escalinata adosada al primer muro, más elaborada, fue al parecer construida en una época contemporánea al segundo muro. La tercera restructuración corresponde a edificaciones de la cultura Huarpa [...] (Lumbreras 1974: 68).

A partir de ello, resume tres fases: «En las capas DD y D1 encontramos cerámica anaranjada, a la que estamos llamando Andamarca y en las superiores cerámica de los tipos Kichka Pata y Chupas. Una situación similar se encontró en el sector norte de Chupas, llamado Raqay Pampa, en donde la capa A era del periodo Huarpa, la capa B probablemente asignable a Rancha y Chupas, la capa C del periodo Kichka Pata y la D del periodo Pre-Chavín de Ayacucho» (Lumbreras 1974: 70). Haciendo una interpretación, la Arquitectura II respondería a la fase Chupas (Período Formativo Final) o, en todo caso, estaría asociada con una remodelación durante la parte tardía del Período Formativo Tardío; y el Edificio I, a la fase Kichkapata del Período Formativo Tardío.

En Ayacucho, la «La Fase Chupas tiene mucho que ver con la cultura Paracas de la región de Ica en la costa; su existencia nos plantea la necesidad de estudiar Ayacucho permanentemente en relación con Ica-Pisco. Este hecho evidente no significa, por supuesto, que sólo a partir de este momento se dieron relaciones entre ambas zonas, lo que creemos nosotros que existió siempre» (Lumbreras 1974: 78). Comparando la cerámica de esta época con Ica, se advierte que los rasgos de Chupas corresponden a la fase Isla de Wallace (1962) y a las fases 5-8 de Menzel, Rowe y Dawson (1964). El felino típico de la cerámica ocucaje-paracas está presente en Chupas, al igual que las formas y técnicas, etc. (Lumbreras 1974: 83). También, está relacionado con la fase A de Cerrillos (Wallace 1962: 308) y con la fase I (Teojate) de Engel (Cruzatt 1971: 628-629). Del mismo modo, Lumbreras, durante sus excavaciones en Wichqana, halló unos entierros de cabezas humanas que estratigráficamente estarían asociadas a capas con cerámica ocucaje 6-8 (1974: 64). Es de mencionar que Casafranca (1960: 333) en Chupas advierte la presencia de una cerámica con la técnica negativa. Por su descripción, podría asociarse con el estilo Ocucaje 4 y 5; sin embargo, no se le dio mucha importancia. 
En resumen, la presencia de cerámica paracas en Ayacucho es trascendente, porque aparece asociada a todos los sitios del Período Formativo — en la cronología de Kaulicke, desde la parte final del Período Formativo Medio hasta el Período Epiformativo- . No obstante, lo que no está claramente definido son las sucesiones de ocupaciones. Es decir, no todos los sitios pudieron haberse ocupado sincrónicamente; otros podrían tener cerámica paracas temprano y otros tardío, como ocurre con Campanayuq Rumi y Pallaucha. Según Matsumoto y Cavero (2009), Campanayuq Rumi se abandona a finales del Período Formativo Tardío; mientras tanto, la población sigue ocupando Pallaucha hasta el Período Epiformativo. Son casos que deberán ser evaluados más a detalle. El abandono de Campanayuq Rumi estaría directamente relacionado con el fenómeno Chavín (Matsumoto y Cavero 2009). No obstante, la ocupación continua de Pallaucha durante el Período Formativo Final y el Período Epiformativo sugiere consideraciones diferentes. Tal vez, los cambios que ocurrieron en territorios lejanos no fueron paralelos a los eventos de esta cuenca.

Aparte de la arquitectura monumental en la zona, se ha logrado determinar el patrón de asentamientos de los poblados asociados a estos sitios. En su mayoría, se resume que tratan de estructuras circulares, como en el caso de Pallaucha (Mendoza 2012) y Campanayuq Rumi (Matsumoto y Cavero 2013). Estos son diferentes a la costa sur, donde predominan construcciones ortogonales (Kaulicke 2013: 288). Reindel et al. realizan investigaciones en las cabezadas de la costa; entrando a la sierra, donde encuentra una ocupación intensa paracas, como patrón de asentamiento, halla conjuntos circulares con estructuras en «D» (2015: 39). A partir de ello, concluye que los conjuntos circulares del Período Paracas conforman un modelo arquitectónico y patrón de asentamiento recurrentes y típicos de la zona de la sierra sur del Perú. Sobre la función, sugiere que estos sirvieron como sitios de acopio y procesamiento de materias primas (Reindel et al. 2015: 58). En este sentido, es interesante estudiar el área de Ayacucho para entender a esta cultura costeńa.

Sin embargo, es aún muy discutida la relación de esta con Chavín, y cómo interactuaron con las culturas locales. En relación con ello, Kaulicke indica que pareciera que la costa sur recibe impulsos iniciales de la costa norte (Cupisnique) ante la emergencia de nuevas formas de élites en esta región. Para el Período Formativo Tardío en el caso de Ayacucho, parece tratarse de un fortalecimiento de nexos económicos, debido a intereses de élites en productos como obsidiana, lana y — probablemente- otros productos, como metales, piedras semipreciosas y otros por determinar. En este sentido, Ayacucho, como otros núcleos en Huancavelica (cinabrio) y Huancayo/Jauja, deben haber cobrado importancia. La cerámica janabarriu probablemente solo es un producto colateral que documenta la intensificación de los contactos serranos. No hay necesidad de pensar que esta se haya formado inicialmente en Chavín de Huántar ni que sea indicadora de la difusión de algún tipo de culto (Kaulicke 2013: 289). En el caso de Pallaucha, no hemos encontrado evidencias de carácter netamente ceremonial; al contrario, lo ceremonial aparece junto con la doméstica y con las áreas de producción. Asimismo, el porcentaje de la cerámica janabariu es bastante reducido.

\section{Consideraciones finales}

La investigación realizada en el sitio de Pallaucha plantea las siguientes conclusiones. En primer lugar, a partir de las excavaciones realizadas en Pallaucha, hemos definido una secuencia cultural que viene desde el Período Formativo (800 a.C a 150 d.C) hasta el Intermedio Tardío (900 a 1496 d.C). La ocupación más importante responde al Período Formativo. Estas ocupaciones siempre están asociadas al material cultural paracas, lo que indica la importancia de esta zona para Paracas o de los Pallauchanos frente a la costa.

En segundo lugar, el patrón de asentamiento en el que se halló esta cerámica paracas (Temprano y Medio) básicamente responde a estructuras circulares y están organizadas irregularmente. Sin excavaciones en área, es difícil determinar patrones de organización. Estas estructuras, en parte, son similares a los encontrados en asentamientos del Período Intermedio Tardío. 
En tercer lugar, se concluye que Pallaucha se encuentra ubicada en un territorio con varios recursos: tiene áreas con amplios bofedales y lagunas, que serían favorables para la crianza de camélidos, los mismos que se utilizarían para el transporte y para la obtención de carne (charki). Así también, en las cercanías de Pallaucha, hay recursos minerales — como oro, cobre, sal—, que se explotan en la actualidad. En las excavaciones, se ha encontrado un nódulo de cobre natural y artefactos, los que sugeriría que estos grupos ya conocían este mineral.

En cuarto lugar, se nota que otro factor importante de intercambio pudo estar conformado por las canteras de obsidiana de Quispisisa, que se hallan en el camino de paso o intermedio de Vilcashuamán con la costa de Paracas. Finalmente, es preciso acotar que, a pesar de la presencia de cerámica paracas, es medir el grado de intensidad de ocupación en la zona.

\section{Agradecimientos}

Quiero iniciar agradeciendo al Ministerio de Cultura por haber aprobado los permisos para realizar las excavaciones en Pallaucha. Asimismo, quisiera agradecer a Aïcha Bachir Bachar y Jahl Dulanto por haberme invitado al II Simposio de Arqueología de la Costa Sur; al doctor Peter Kaulicke, asesor de mi tesis de maestría en la PUCP, la cual forma parte este trabajo; a Yuichi Matsumoto y Yuri Cavero por haberme permitido participar en su proyecto de investigación en Campanayuq Rumi; y a José Ochatoma y Martha Cabrera por su motivación para seguir investigando. Finalmente, agradezco a los estudiantes de Arqueología de la UNSCH, quienes participaron en las excavaciones: Edwin Guerreros, Eduar Gutiérrez, Michael Mendoza, Ivan Vivanco, Ivan Mendieta, Angel Ticlla, Gregori Ccenta, Yennifer Naccha, Ronal Mendoza, Hilda Bellido y Walter Najarro.

\section{REFERENCIAS}

Burger, R. L.

1989 El horizonte Chavín: ¿Quimera estilística o metamorfosis socioeconómica? Revista Andina 14, 543-574.

1993 Emergencia de la Civilización en los Andes: ensayos de Interpretación, Universidad Nacional Mayor de San Marcos, Lima.

2012 Central Andean language expansion and the Chavin sphere of interaction, Proceedings of the British Academy 173, 133-159.

Burger, R. y R. Matos

2002 Atalla: a center on the periphery of the Chavin Horizon, Latin American Antiquity 13 (2), 153-177.

Carrera, P., G. Farfán y M. González

2014 Expedición arqueológica a la cuenca del río Pampas, Museo Nacional de Antropología y Arqueología, [1945-1946] Lima [Reeditado en: Revista Conchopata 4, 11-56, UNSCH, Ayacucho].

Casafranca, J.

1960 Los nuevos sitios arqueológicos chavinoides en el departamento de Ayacucho, en: R. M. Matos (ed.), Antiguo Perú: espacio y tiempo, 325-334, Editorial Juan Mejía Baca, Lima.

Cruzatt, V. A.

1971 Horizonte Temprano en el valle de Ayacucho, Anales Cientificos 1, 603-631.

Flores, I.

1960 Wichqana: sitio temprano en Ayacucho, en: R. Matos M. (ed.), Antiguo Perú: espacio y tiempo, 335-344, Mejía Baca, Lima.

Guzmán Ladrón de Guevara, C.

1959 Proyecto de exploración del sitio arqueológico de Willca Waman, departamento de Ayacucho, tesis de bachiller, Universidad Nacional Mayor de San Marcos, Lima.

Kaulicke, P.

2010 Las cronologias del Formativo. 50 años de investigaciones japonesas en perspectiva, Fondo Editorial de la Pontificia Universidad Católica del Perú, Lima. 
2013 Paracas y Chavín: variaciones sobre un tema longevo, A. Bachir Bacha y J. Dulanto (eds.), Paracas: nuevas evidencias, nuevas perspectivas, Boletin de Arqueología PUCP 17, 269-296.

Lumbreras, L. G.

1959 Esquema arqueológico de la sierra central del Perú, Revista del Museo Nacional 28, 63-116.

1974 Las fundaciones de Huamanga. Hacia una prehistoria de Ayacucho, homenaje al sesquicentenario de la batalla de Ayacucho, Club de Huamanga, Nueva Escuela, Lima.

1981 The stratigraphy of the open sites, en: R. S. MacNeish, A. G. Cook, L. G., Lumbreras, R. K. Vierra y A. N. Terner (eds.), Prehistory of the Ayacucho Basin, Peru, Volume II: excavations and chronology, The University of Michigan Press, Ann Arbor.

MacNeish, R. S., A. G. Cook, L.G. Lumbreras, R. K. Vierra y A.Nelken-Terner

1981 Prehistory of the Ayacucho Basin, Peru, Volume II: excavations and chronology, Robert S. Peabody Foundation for Archaeology, The University of Michigan Press, Ann Arbor.

Matsumoto, Y.

2010 The Prehistoric ceremonial center of Campanayuq Rumi: interregional interactions in the South-central Highlands of Peru, tesis de doctorado, Department of Philosophy, Yale University, New Haven.

Matsumoto, Y. y Y. I. Cavero

2009 Una aproximación cronológica del centro ceremonial de Campanayuq Rumi, Ayacucho, . Kauilicke y Y. Onuki (eds.), El Período Formativo: enfoques y evidencias recientes. Cincuenta años de la Misión Arqueológica Japonesa y su vigencia, Boletín de Arqueología PUCP 13, 323-346.

Mendoza, E.

2010 Investigaciones arqueológicas en la margen izquierda de los ríos Yanamayu y Pampas, VilcashuamánAyacucho, Revista Pacha Runa 1, 123-162.

2012 Proyecto de Investigaciones Arqueológicas «Pallaucha» Vilcashuamán, Ayacucho, informe final presentado al Ministerio de Cultura, Lima.

Menzel, D., J. H. Rowe y L. E. Dawson

1964 The Paracas pottery of Ica: a study in style and time, University of California Publications in American Archaeology and Ethnology 50, University of California Press, Berkeley.

Ochatoma, J. A.

1998 El Formativo en Ayacucho: balances y perspectivas, en: P. Kaulicke (ed.), Perspectivas regionales del Período Formativo en el Perú, Boletín de Arqueología PUCP 2, 289-302.

Pérez, I., M. Purizaga y F. León

2007 Vilcashuamán: paisaje, historia y cultura, Oficina de Investigación, Universidad Nacional San Cristóbal de Huamanga, Ayacucho.

Pozzi-Escot, D. y C. R. Cardoza

1986 El consumo de camélidos entre el formativo y wari, en Ayacucho, Instituto Andino de Estudios Arqueológicos (de la Universidad Nacional de San Cristóbal de Huamanga), Lima.

Pulgar, J.

1981 Geografía del Perú: las ocho regiones naturales del Perú, 8va edición, Editorial Universo S.A., Lima.

Reindel, M., J. Isla y H. Otten

2015 Paracas en Palpa: los fundamentos del poder de la cultura, Peruvian Archaeology 2, 37-64, The Yamagata University Institute of Nasca, the Faculty of Literature and Social Sciences, Japan.

Recepción: marzo de 2017 Aceptación: mayo de 2017 